\title{
Studies on the relationships of the Curie surface with heat flow and crustal structures in Yunnan Province, China, and its adjacent areas
}

\author{
Limin Wen, Guofa Kang, Chunhua Bai and Guoming Gao*
}

\begin{abstract}
A Curie surface indicates the distribution of the thermal fields underground, providing a clear marker for the thermodynamic effect in the crust and mantle. In this paper, based on a geomagnetic field model (NGDC-720) and aeromagnetic data, we use power spectrum analysis of magnetic anomalies to estimate the Curie surface in Yunnan Province, China, and its adjacent areas. By combining the distribution of the Curie surface with regional heat flow, the geothermal gradient, crustal wave velocity ratio anomalies, high-conductivity layer anomalies, and the Moho surface, we reveal the connection between the undulation of the magnetic basement and the crustal structures. The results indicate that the uplift and depression of the Curie surface in the research area are distinct. The Curie surface is approximately inversely correlated to the surface heat flow. The Lijiang-Jianchuan-Baoshan-Tengchong and Jianchuan-Chuxiong-Kunming-Yuxi zones are two Curie surface uplift zones, and their crust-mantle heat flows are relatively high. The Curie surface uplift zone along the Lijiang-Xiaojinhe fault and Red River fault is consistent with the heading direction of the fault zone and is partially in agreement with the eastward mass flow of the Tibetan Plateau. The Curie surface uplift zone is consistent with the high wave velocity ratio and high-conductivity layer anomaly region of the crust. The depth of the Curie surface is less than the depth of the Moho surface.
\end{abstract}

Keywords: Lithospheric magnetic field, Curie surface, Heat flow, Crustal structure, Yunnan Province and its adjacent area

\section{Introduction}

The Earth's lithospheric magnetic field originates from the magnetism of rocks in the crust and upper mantle with a temperature lower than the Curie point (approximately $580{ }^{\circ} \mathrm{C}$ ). Due to the difference in the magnetization characteristics of rocks and tectonic evolution, the lithospheric magnetic field carries important information about the composition of the crustal matter and tectonic evolution (Gao et al. 2013; Thébault et al. 2010; Xu 2009).

A Curie point isothermal surface (called a Curie surface) is created by ferromagnetic minerals in crustal rocks becoming a paramagnetic interface when the

*Correspondence: gmgao@ynu.edu.cn

Department of Geophysics, Yunnan University, 2 North Green Lake Rd. Kunming 650091, Yunnan, People's Republic of China temperature reaches the Curie point. A Curie surface is not only the lower interface of the magnetic crustal thickness but also an important thermodynamic interface inside the Earth. The Curie surface varies from region to region, mainly depending on the regional geology, the geothermal flow, and the mineral content in rock (Bilim et al. 2016; Gao et al. 2019; İbrahim et al. 2005; Manea and Manea 2011; Salazar et al. 2017; Yury et al. 2018). Studies of the Curie surface can reflect the deep structures of a magnetic substance and improve the understanding of regional geological tectonics and evolution (Rajaram et al. 2009). In addition, the Curie surface can provide valuable insight into the assessment of geothermal energy, oil, gas, and mineral resources, as well as the exploration of seismic origin (Nyabeze and Gwavava 2016; Utada et al. 2000; Zhang et al. 2017). 
Estimating the Curie surface is mainly based on geothermal and magnetic field methods (Eppelbaum and Pilchin 2006; Hamed and Nabi 2012). The geothermal method is based on geothermal data of terrestrial heat flow, geothermal gradients, and thermal conductivity. Its disadvantage is that it cannot directly measure the geothermal parameters at a relatively large depth (Gao et al. 2017, 2018; Tanaka et al. 1999). There are many factors that affect the depth of a Curie surface, including the surface heat flow, the geothermal gradient, the rock heat generation rate, mantle heat flow, fault activity, and the composition of rock physical properties. However, regardless of how the aforementioned parameters change, the undulation of the magnetic interface is always reflected in the magnetic anomaly data. Therefore, the most common and easily obtained aeromagnetic anomaly or satellite magnetic anomaly data are usually used to calculate the Curie surface (Rajaram et al. 2009; Ravat et al. 2007).

The traditional computation method of the Curie surface uses aeromagnetic measurement data. However, these data are susceptible to various sources of errors, such as navigational and/or altimetric mislocation and the improper removal of regional and external fields. If regional fields are not removed properly and consistently from individual surveys, it will be difficult to compile a unitive and high-quality magnetic anomaly map of a large area. Aeromagnetic surveys are often flown at relatively low heights; thus, the magnetic fields caused by the surface sources suppress the signals coming from the deep crust (Abramova et al. 2013). This suggests that a well-built and statistically validated model (e.g., NGDC720-v3) is better for studying the deep basement (e.g., estimating a lower boundary of the magnetic layer in the crust) than aeromagnetic data compiled from different sources (Arnaiz-Rodríguez and Orihuela 2013; Gao et al. 2015a).

Since the 1980s, the application of satellite magnetic survey data to estimate the Curie surface has substantially progressed (Mayhew 1982; Purucker et al. 1998; Purucker and Clark 2011). Based on the equivalent magnetic dipole method, Maule et al. (2005) used the lithospheric magnetic field model of the CHAMP satellite magnetic surveys (MF3 and MF5) to calculate the depth of the Curie surface for Australia, Antarctica, and Greenland, as well as estimate the density of the terrestrial heat flow. Rajaram et al. (2009) used the MF5 model to calculate the distribution of the Curie surface under the Indian subcontinent, which has the same variation trend as the Curie surface obtained using aeromagnetic anomaly data and agrees with the tectonic trend of the main geotectonic units of the Indian subcontinent. The satellite magnetic anomaly is a long-wavelength anomaly and reflects the magnetic distribution for the rocks on the top of the lower crust and upper mantle. Therefore, we can only give the large-scale variation trend for a Curie surface estimated using the satellite magnetic anomaly because it does not reflect the undulating features of the local Curie surface. With progress in satellite magnetic survey and data processing techniques, the application of a high-order magnetic field model constructed using satellite, aviation, ocean, and ground surface magnetic survey data has recently provided very good estimates of the Curie surface (Arnaiz-Rodríguez and Orihuela 2013; Gao et al. 2015b, c; Salazar et al. 2017).

Yunnan Province and its adjacent area are located on the southeastern Tibetan Plateau, and the region is a marginal zone for the convergence and interaction between the Eurasian and Indian plates (Fig. 1) (Chang et al. 2015; Xu et al. 2013; Xue et al. 2017). In this region, the geological structure is complicated, and the transverse inhomogeneity of the medium is strong. Moreover, intense earthquakes have frequently occurred. Studies on earthquakes, telluric electromagnetic sounding, and surface heat flow indicate that the low crustal wave velocity layer, high-conductivity layer, high wave velocity ratio and high heat flow region are universally present in the Yunnan area (Hu et al. 2018; Wang et al. 2017; Wen et al. 2019). The characteristics of the crustal layer revealed by these geophysical methods are all related to the crustal thermal state. Investigations into the connection between the undulation of the Curie surface and crustal structures are important for an in-depth understanding of the geological tectonics and geodynamic process, as well as for an exploration of seismic origin (Manea and Manea 2011; Ravat et al. 2007; Saada 2016).

In this paper, according to the magnetic field model called NGDC-720 established by combining data from satellite, marine, aeromagnetic, and ground magnetic surveys (Maus et al. 2009; Maus 2010a, b), we calculate the Curie surface in Yunnan Province and its adjacent areas. Then, the relationship between the undulation of the magnetic basement and the crustal structures is elucidated, followed by a discussion of the terrestrial heat flow, geothermal gradient, Moho surface, crustal high-conductivity layer, and seismic wave velocity ratio anomalies.

\section{Research background}

Yunnan Province and its adjacent area are located at the composite site of the Tethys-Himalaya tectonic domain and coastal Pacific tectonic domain. It is a frontier zone and a deep mass flow zone for the northeast-trending collisional extrusion of the Indian plate and Eurasian continent (Fig. 1) (She and Fu 2019; Xu et al. 2013). From the perspective of plate tectonics, due to the collision of the nearly SN-trending subducting Indian plate and Eurasian continent, the northern side of the Tibetan 


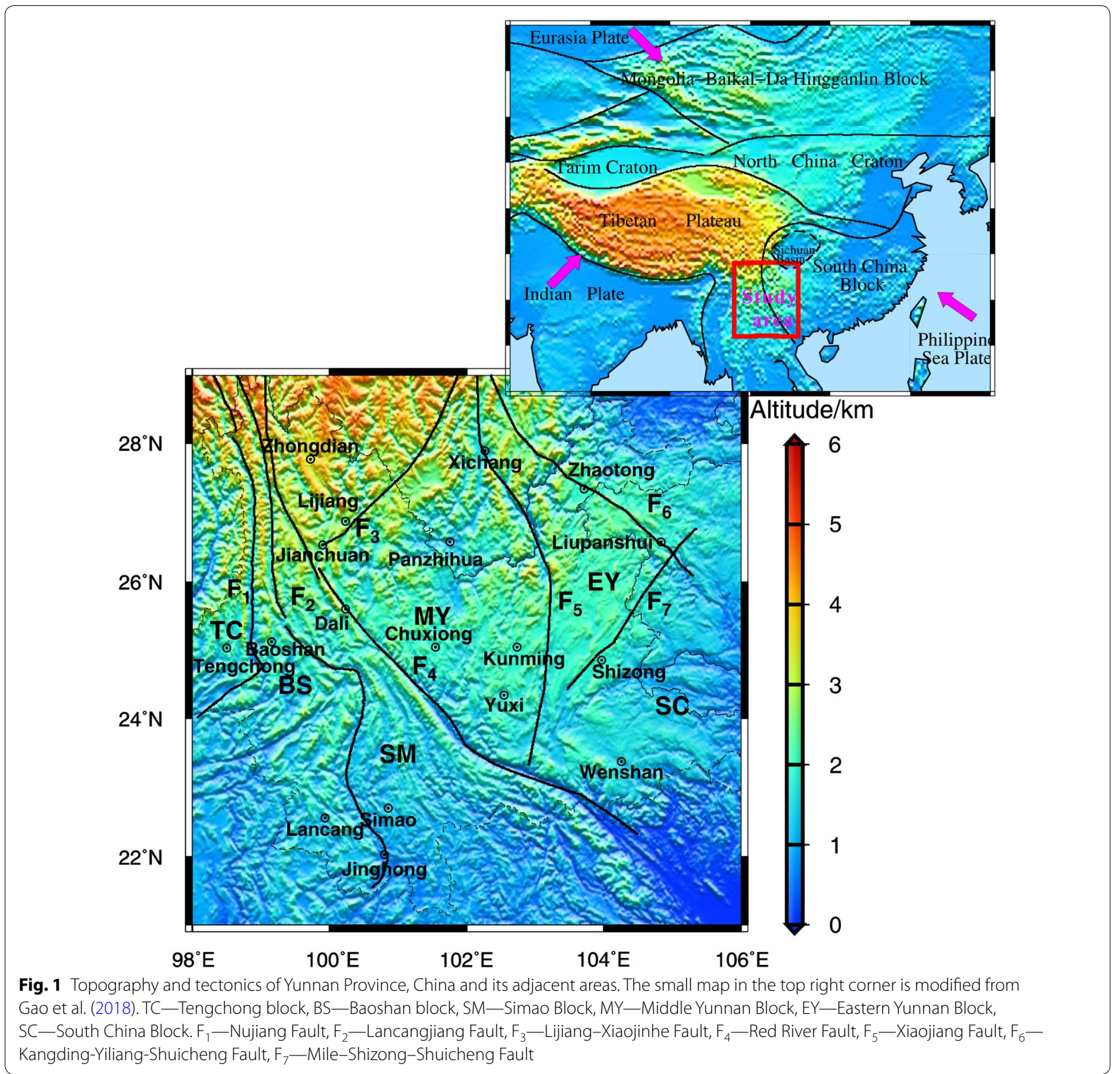

Plateau is blocked by the Siberian platform. On the one hand, the crust of the plateau became thicker to absorb the strong compression action in the north-south direction. On the other hand, the crust exhibited a mass flow channel in the east-west direction (Burchfiel and Wang 2003; Schoenbohm et al. 2006). In addition, the Sichuan Basin acted as a high strength block and obstructed the mass flow. Therefore, the eastward mass flow diverges toward the northeast and southeast directions. The research area is located in the southeastern region of the plateau that incorporates the important southeastward mass flow of the plateau. This area is key for investigating intracontinental deformation caused by the Indian-Eurasian plate collision and the dynamic process.

The intense orogeny and large-scale strike-slip fault activity make the geological structure in the research area very complicated, i.e., the complicated tectonic pattern of the Cenozoic orogenic zones in western Yunnan and Sanjiang and the central Yunnan subsidence basin. The deep large faults, including the Nujiang fault $\left(\mathrm{F}_{1}\right)$, Lancangjiang fault $\left(\mathrm{F}_{2}\right)$, Lijiang-Xiaojinhe fault $\left(\mathrm{F}_{3}\right)$, Red River fault $\left(\mathrm{F}_{4}\right)$, Xiaojiang fault $\left(\mathrm{F}_{5}\right)$, Kangding-Yiliang-Shuicheng fault $\left(\mathrm{F}_{6}\right)$ and Mile-Shizong-Shuicheng fault $\left(\mathrm{F}_{7}\right)$ from west to east, intertwine in the research area (Bai et al. 2010). These 
fault zones divide the tectonic units of the Yunnan area into the Tengchong block, Baoshan block, Simao block, Middle Yunnan block, and Eastern Yunnan block (Bai et al. 2010; Wang and Li 2015; Wen et al. 2017).

The Middle Yunnan block (also known as rhombic block) is confined by the Lijiang-Xiaojinhe fault $\left(\mathrm{F}_{3}\right)$, Red River fault $\left(\mathrm{F}_{4}\right)$, and Xiaojiang fault $\left(\mathrm{F}_{5}\right)$, representing the main part of the southeast extrusion of the Tibetan Plateau. Its crustal deformation is mainly controlled by the boundary fault zone (Chen et al. 2000; Wang and Burchfiel 2000; Wang and Li 2015). The main structures of the $\operatorname{Nujian}\left(\mathrm{F}_{1}\right)$, Lancangjiang $\left(\mathrm{F}_{2}\right)$, and Red River $\left(\mathrm{F}_{4}\right)$ fault zones in western Yunnan are nearly south-north trending. This area is considered to be an important channel for the eastern flow of material on the Tibetan Plateau (Guan et al. 2004; Replumaz and Tapponnler 2003; Shi et al. 2015). Belonging to the Bomi-Tengchong fold system, the Tengchong block is a Cenozoic active volcanic area and is also a part of the Tengchong-Longling seismic belt (Wang et al. 2002). Located between the Nujiang $\left(F_{1}\right)$ and Lancangjiang $\left(\mathrm{F}_{2}\right)$ faults, the Baoshan block narrows gradually from south to north. The Simao block between the Lancangjiang fault $\left(\mathrm{F}_{2}\right)$ and Red River fault $\left(\mathrm{F}_{4}\right)$ is a continuation of the northern part of the Indosinian block. The irregular boundary shape is related to Cenozoic deformation and transformation (Leloup et al. 1995). The eastern part of the Xiaojiang fault $\left(\mathrm{F}_{5}\right)$ belongs to the Eastern Yunnan block, which is mainly influenced by the activity of the Xiaojiang fault $\left(\mathrm{F}_{5}\right)$ zone (Chen et al. 2013; Wang and Li 2015).

The research area is part of the southern segment of the southern and northern seismic zones of mainland China. Due to the influence of dual dynamic actions, including the eastward subduction of the Indian plate along the Yunnan-Burma arc and the lateral compression of the Tibetan Plateau block, intense earthquakes have been frequent; the internal seismic activity of this region is one of the strongest in mainland China (Zhang, 2013). The focal depth of most earthquakes is in the range of $5-25 \mathrm{~km}$, which is in the range of the upper and middle crusts. Studies on earthquakes and gravitational anomalies indicate that near $28^{\circ} \mathrm{N}$ along the southeastern part of the Tibetan Plateau, the velocity of seismic waves is abnormal, and the crustal density has different characteristics (Lou and Wang 2005; Shen et al. 2015).

The area west of the Lancangjiang fault $\left(\mathrm{F}_{2}\right)$ in western Yunnan Province is part of the Himalayan high geothermal zone, and it belongs to the subduction zone of the Myanmar-Andaman plate. It has the characteristics of an arc-type high geothermal zone and is a modern volcanic geothermal region with very active geological tectonics (Hemant and Mitchell 2009). In particular, the Tengchong area, which has the most intense new tectonic movement, is also one of the regions with modern volcanic activity in China. The research area has many observation sites of heat flow because many studies of earthquakes and geothermal resources have been performed in this area.

There are previous studies on the Curie surface of Yunnan Province and its adjacent areas. Shen et al. (1986) used aeromagnetic data to estimate the Curie point depth in the area of the Kangdian continental rift valley belt. Xiong et al. $(2014,2016)$ presented a map of the depth of the Curie surface in mainland China and analyzed the distribution characteristics of the magnetic basement. Although these studies cover the research area, the range of these studies is too large, and the measurements only reflect the rough trend of changes in the Curie surface. It is difficult to meticulously describe the undulation features of the Curie surface and its connection to the regional tectonics.

Since the 1980s, to study the geodynamic mechanism and strong continental seismic background in Yunnan Province and its adjacent areas, extensive geophysical observations and research of earthquake, gravity, and telluric electromagnetic soundings have been conducted. Seismological exploration has revealed a stratified structure, seismic wave velocity anomaly, and Poisson's ratio distribution of the crust (Wang et al. 2002; Xue et al. 2017). The gravity method has been used to characterize the gravitational anomaly and nonuniformity characteristics of the crustal density (Lou and Wang 2005; Shen et al. 2015). The telluric electromagnetic sounding profile has shown that the lower crust in this region is mainly a low-resistance layer (Bai et al. 2010; Cheng et al. 2015; Wang et al. 2017). Generally, studies on geology, earthquakes, and crustal layer in this region have been very thorough, but studies that use a magnetic anomaly to estimate the Curie surface are still very insufficient. The aforementioned research results of geophysical methods provide useful reference information for investigating the Curie surface, lithospheric thermal state, and crustal structures.

\section{Data and method \\ Magnetic data}

According to the theory of the geomagnetic field potential function, the geomagnetic potential can be expressed as a spherical harmonic series:

$$
\begin{aligned}
U(r, \theta, \lambda) & =a \sum_{n=1}^{N} \sum_{m=0}^{n}\left(\frac{a}{r}\right)^{n+1}\left(g_{n}^{m} \cos m \lambda\right. \\
& \left.+h_{n}^{m} \sin m \lambda\right) P_{n}^{m}(\cos \theta),
\end{aligned}
$$

where $r, \lambda$, and $\theta$ are radius, longitude, and latitude, respectively, $a$ is the average radius of the Earth 


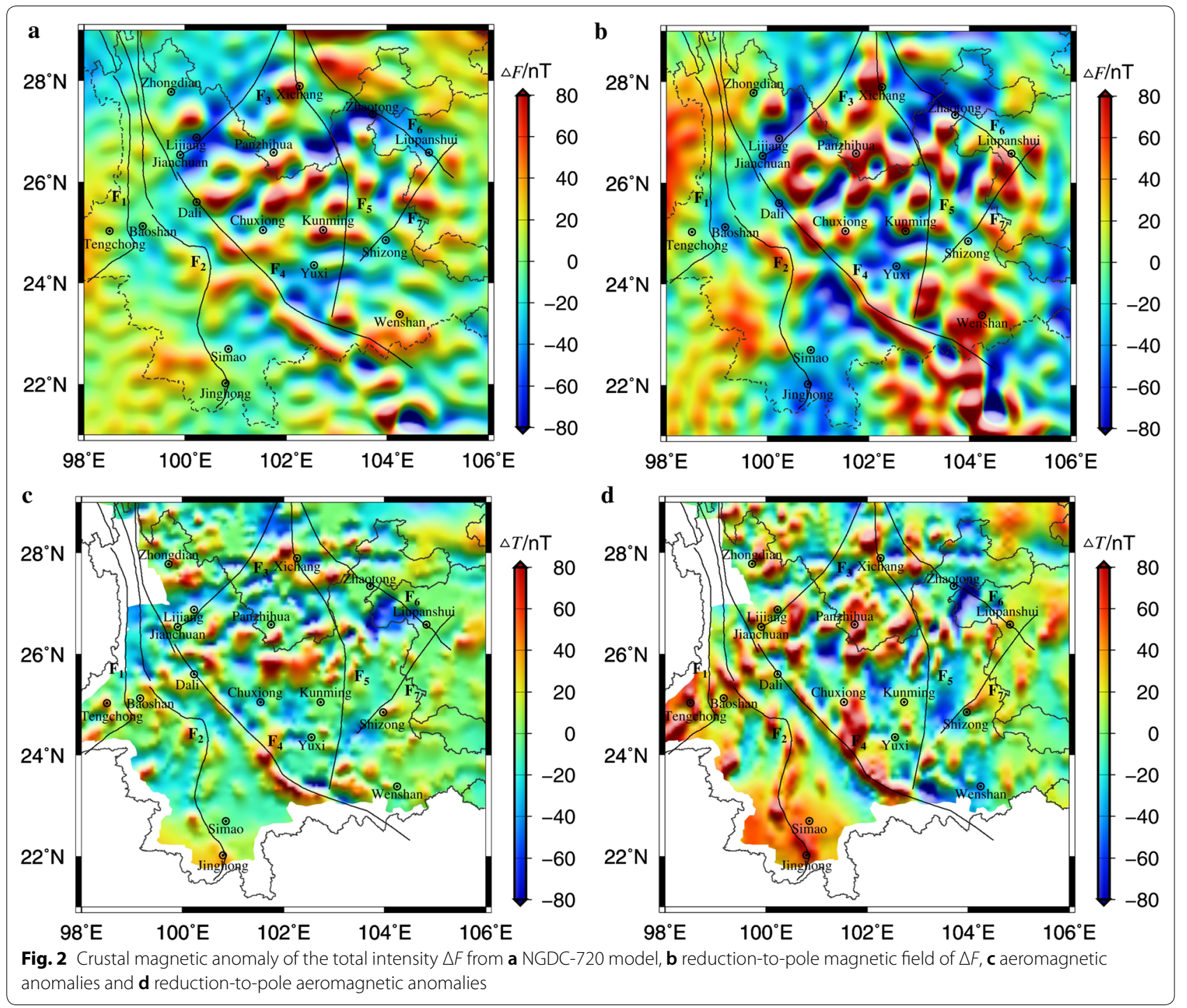

(6371.2 km), $P_{n}^{m}(\cos \theta)$ are the Schmidt quasi-normalized associated Legendre functions of degree $n$ and order $m$, $g_{n}^{m}$ and $h_{n}^{m}$ are spherical harmonic coefficients, and $N$ is a truncation level. The geomagnetic potential function is differentiated in the spherical coordinate system to obtain 3 rectangular coordinate components of the geomagnetic field in the north direction $X$, the east direction $Y$, and the vertical direction $Z$, and the total geomagnetic field intensity $F=\sqrt{X^{2}+Y^{2}+Z^{2}}$. In the spherical harmonic series of the geomagnetic field, the part with spherical harmonic orders $n \leq 15$ is the core magnetic field, and that with $n \geq 16$ is mainly the crustal magnetic field (Thébault et al. 2010).

In this paper, we use the NGDC-720 model to calculate the magnetic anomalies of the crust. In the calculation of the total crustal magnetic field intensity $\Delta F$ using the POMME-6.2 model, the total magnetic field $F$ of orders $n=1-720$ and the core main magnetic field $F_{\mathrm{m}}$ of orders $n=1-15$ are calculated, and then, the core main magnetic field is subtracted from the total magnetic field to obtain the difference $\left(\Delta F=F-F_{\mathrm{m}}\right)$, which is the crustal magnetic field $\Delta F$.

To compare the difference between the crustal magnetic fields calculated by the model and the aeromagnetic anomalies, we digitize and expand the data in the 1:5,000,000 magnetic anomaly map of aviation in China and the adjacent sea area at an altitude of $1 \mathrm{~km}$ compiled by the China National Land and Resources Aeronautical Geophysical Exploration Remote Sensing Center in 2004 to obtain the distribution of the aeromagnetic anomalies on the ground surface (Fig. 2b). We can see from Fig. 2 that although there are some differences at certain sites, the distribution trends of the strong and weak anomalies are consistent. Due to the limitation of national 
boundaries, there are blanks present in the aeromagnetic data in the region beyond the border of China. In addition, the aeromagnetic data are measured at low altitude, and the magnetic anomaly generated by the shallow magnetic body suppresses the information about the magnetic field generated by the deep magnetic source. Consequently, the study of the distribution of the deep magnetic basement through aeromagnetic anomalies is limited. Thus, we use a high-order geomagnetic field model constructed using satellite, ground surface, ocean, and aeromagnetic data. Through unified spatiotemporal processing, we can calculate the magnetic anomaly at different layers from the ground surface to the height of the satellite. Therefore, in this paper, we use the magnetic anomalies calculated with the NGDC-720 model to estimate the Curie surface.

In the geomagnetic measurements, due to the influence of inclined magnetization, there could be a shift in the characteristic location of a magnetic anomaly. This shift could cause some difficulty in determining the spatial location, morphology, and distribution range for the magnetic geological body and explaining the magnetic anomaly. For the convenience of interpreting the magnetic survey data and to directly reflect the information of the spatial location and morphology for a magnetic geological body, the inclined magnetization is converted to the vertical magnetization (Arkani-Hamed 2007). In this paper, we adopt the differential reduction-to-pole method with variable geomagnetic inclination to convert the magnetic anomalies over the entire region (Cooper and Cowan 2005; Lu et al. 2003). This method applies perturbations in the space domain. Using a Taylor series expansion,

$$
\begin{aligned}
\mathrm{RTP}_{\text {var }}= & \mathrm{RTP}_{\text {mean }}+\Delta \mathrm{inc} \frac{\partial \mathrm{RTP}}{\partial \mathrm{inc}}+0.5 \Delta \mathrm{inc}^{2} \frac{\partial^{2} \mathrm{RTI}}{\partial \mathrm{inc}^{2}} \\
& +\Delta \operatorname{dec} \frac{\partial \mathrm{RTP}}{\partial \operatorname{dec}}+0.5 \Delta \operatorname{dec}^{2} \frac{\partial^{2} \mathrm{RTP}}{\partial \operatorname{dec}^{2}}+\cdots,
\end{aligned}
$$

where $\mathrm{RTP}_{\text {mean }}$ is the dataset reduced to the pole using the average field inclination and declination of the area, $\Delta$ inc is the difference between the inclination at a given point and the average inclination, and $\Delta \mathrm{dec}$ is computed similarly. The derivatives are computed in the space domain by differencing. Figure $2 \mathrm{~b}$, $\mathrm{d}$ shows the anomaly maps of the reduction-to-pole magnetic field of $\Delta F$ on the ground surface from NGDC-720 and from the aeromagnetic anomalies, respectively. A comparison of Fig. 2a, b shows that the magnetic anomaly distribution shapes are obviously different before and after the reduction to the pole. The most obvious change is that there is a positive and negative magnetic anomaly border clearly shown between the Longmenshan and Lijiang-Xiaojinhe fault $\left(\mathrm{F}_{3}\right)$ zones after reduction to the pole (Fig. 2b). In the following, we focus on the magnetic anomaly features after the reduction to the pole.

The distribution of the magnetic anomalies in the research area has obvious zoning characteristics (Fig. 2). The Lijiang-Xiaojinhe fault $\left(\mathrm{F}_{3}\right)$ and Red River fault $\left(\mathrm{F}_{4}\right)$ are the positive-negative boundaries of the magnetic anomaly. The Kangding-Yiliang-Shuicheng fault $\left(\mathrm{F}_{6}\right)$ and Mile-Shizong-Shuicheng fault $\left(\mathrm{F}_{7}\right)$ are the boundaries of the strong and weak transition zones. These four faults are the rhomboid block boundaries. The distribution of the magnetic anomaly in the rhomboid block is complicated, in which positive and negative magnetic anomalies appear alternately. In the region outside the rhomboid block, especially the region to the west of the Lijiang-Xiaojinhe fault $\left(\mathrm{F}_{3}\right)$ and Red River fault $\left(\mathrm{F}_{4}\right)$, the magnetic anomaly is relatively weak. Along the region near the Red River fault $\left(\mathrm{F}_{4}\right)$ zone, there is a distribution of positive and negative magnetic anomalies in a banded zone, which extends to the southeast until the northern region of Vietnam (Hechi area). The heading direction of the fault zone is consistent with the heading direction of the magnetic anomaly. In addition, if we divide according to the structure of seismic activity, the eastern boundary of the Sichuan-Yunnan rhomboid block is usually bordered by the Anning River, Zamuhe fault, and Xiaojiang fault $\left(\mathrm{F}_{5}\right)$ (Kan et al. 1986; Wu et al. 2013). However, the abnormal distribution of $\Delta F$ indicates that there is no obvious change in the magnetic anomaly on both sides of the Xiaojiang fault $\left(\mathrm{F}_{5}\right)$. The region with a relatively strong magnetic anomaly expands to the east of the Xiaojiang fault $\left(\mathrm{F}_{5}\right)$ and is roughly bordered by the KangdingYiliang-Shuicheng fault $\left(\mathrm{F}_{6}\right)$ and Mile-Shizong-Shuicheng fault $\left(\mathrm{F}_{7}\right)$.

\section{Calculation of the Curie isothermal surface}

In this paper, we adopt the power spectrum analysis of magnetic anomalies to estimate the depth of the Curie surface (Maden 2010; Saibi et al. 2015; Tanaka et al. 1999). Suppose that the magnetic body infinitely extends in the horizontal direction. Its vertical depth of burial is very small relative to the horizontal extension scale. The magnetization intensity $M(x, y)$ is a random function of the horizontal directions $x$ and $y$. The power spectrum of the total magnetic field $\Phi_{\Delta T}\left(k_{x}, k_{y}\right)$ can be expressed as follows (Bhattacharyya and Leu 1975):

$$
\Phi_{\Delta T}\left(k_{x}, k_{y}\right)=\Phi_{\mathrm{M}}\left(k_{x}, k_{y}\right)^{\prime} F\left(k_{x}, k_{y}\right),
$$

where $\Phi_{\mathrm{M}}$ is the power density spectrum of magnetization intensity, and $k_{x}$ and $k_{y}$ are wavenumbers in the $x$ and $y$ directions, respectively. 


$$
F\left(k_{\mathrm{x}}, k_{\mathrm{y}}\right)=4 \pi^{2} C_{\mathrm{m}}^{2}\left|\Theta_{\mathrm{m}}\right|^{2}\left|\Theta_{\mathrm{f}}\right|^{2} \mathrm{e}^{-2|k| Z_{\mathrm{t}}} \times\left[1-\mathrm{e}^{-|k|\left(Z_{\mathrm{b}}-Z_{\mathrm{t}}\right)}\right]^{2},
$$

where $C_{\mathrm{m}}$ is the constant of proportionality, $\Theta_{\mathrm{m}}$ and $\Theta_{\mathrm{f}}$ are the magnetization direction factor and geomagnetic field direction factor, respectively, and $Z_{t}$ and $Z_{b}$ are the depths of burial for the upper surface and the lower surface of magnetic substance, respectively. For the various terms in the reduced equation, note that except for the two terms $\left|\Theta_{\mathrm{m}}\right|^{2}\left|\Theta_{\mathrm{f}}\right|^{2}$, all terms exhibit radial symmetry, and the radial average of $\Theta_{\mathrm{m}}$ and $\Theta_{\mathrm{f}}$ is constant. If $M(x, y)$ is a random function, $\Phi_{M}\left(k_{x}, k_{y}\right)$ is also constant. After the appropriate simplification and when the wavelength is smaller than twice the thickness of the magnetic layer, we can obtain an approximate expression of Eq. (4):

$$
\ln \left[\Phi_{\Delta T}(|K|)^{1 / 2}\right]=\ln B-|K| \mathrm{Z}_{\mathrm{t}},
$$

where $D$ is constant. Moreover, Eq. (4) can be written as

$$
\Phi_{\Delta T}(|K|)^{1 / 2}=C \mathrm{e}^{-2|k| Z_{0}}\left(\mathrm{e}^{-|k|\left(Z_{\mathrm{t}}-Z_{0}\right)}-\mathrm{e}^{-|k|\left(Z_{\mathrm{b}}-Z_{0}\right)}\right),
$$

where $C$ is constant. For the long-wavelength segment, Eq. (6) can be written as

$$
\begin{aligned}
\Phi_{\Delta T}(|K|)^{1 / 2} & =C \mathrm{e}^{-2|k| Z_{0}}\left(\mathrm{e}^{-|k|(-d)}-\mathrm{e}^{-|k|(d)}\right) \\
& \approx C \mathrm{e}^{-|k| Z_{0}} 2|k| d,
\end{aligned}
$$

where $2 d$ is the thickness of the magnetic body, and Eq. (7) can be expressed as

$$
\ln \left\{\left[\Phi_{\Delta T}(|K|)^{1 / 2}\right] /|K|\right\}=\ln D-|K| Z_{0},
$$

where $D$ is constant. According to Eqs. (5) and (8), by fitting the slope of a straight line, we can estimate the depth $Z_{t}$ of the magnetic layer top surface and central depth $Z_{0}$, and the depth $Z_{\mathrm{b}}$ of the magnetic layer bottom surface is $Z_{\mathrm{b}}=2 Z_{0}-Z_{\mathrm{t}}$. The depth of the magnetic layer bottom surface obtained by the aforementioned method reflects the average Curie point depth.

Because a shallow-source magnetic anomaly body can generate a local magnetic anomaly with a relatively high abnormal value and relatively high frequency, it can cover the deep geological information to some extent. To suppress the shallow-source magnetic anomaly while emphasizing the deep information, we extend the magnetic anomaly on the ground surface upward and compare and analyze the distribution form and decay rate of the magnetic anomaly at different heights. We select the data of the height layer with slow attenuation of the magnetic anomaly and a steady distribution pattern to calculate the Curie isothermal surface. In this paper, we select the magnetic anomaly at a height extending upward for $15 \mathrm{~km}$ to calculate the depth of the Curie surface.

In the calculation process, we first divide the research area into windows of equal size. The size of the window should be at least 4-6 times the depth of the Curie surface (Dimitriadis et al. 1987; Nwobgo, 1998). Therefore, we select the size of the window to be $1.28^{\circ} \times 1.28^{\circ}$ (approximately $140 \times 140 \mathrm{~km}$ ). We adopt an overlapped sliding window to calculate the entire region, and two adjacent windows are overlapped by $50 \%$. In addition, to increase the abnormal information of the boundary region, we expand the range by $2^{\circ}$ in the actual calculation, i.e., the range of the magnetic anomaly data is $19^{\circ}$ $\mathrm{N}-31^{\circ} \mathrm{N}, 96^{\circ} \mathrm{E}-108^{\circ} \mathrm{E}$ to estimate the depth of the Curie surface. Using Eqs. (5) and (8), we calculate the amplitude spectrum of every window and the ratio between the amplitude spectrum and wavenumber to obtain an estimation value for the buried depth $Z_{\mathrm{t}}$ of the magnetic body top surface and the buried depth $Z_{0}$ of the central point. Therefore, we obtain the depth of the Curie surface $Z_{\mathrm{b}}$ (Fig. 3a). The histogram in Fig. 3a shows the statistical distribution for the depth of the Curie isothermal surface.

To assess the geometry of the Curie surface obtained from the NGDC-720 model, we use the aeromagnetic anomalies in Fig. $2 d$ to calculate the Curie surface. First, to eliminate the influence of shallow magnetic source bodies, the aeromagnetic anomalies were extended upwards to $15 \mathrm{~km}$ above the ground surface by multiplying by an upward prolongation factor in the frequency domain ( $\mathrm{Li}$ et al. 2009). Second, the Curie surface was calculated with the aeromagnetic anomalies using the same method as that for the calculation of the Curie surface with the magnetic anomalies from the NGDC-720 model (Fig. 3b). Figure 3a, b shows that the Curie surface obtained by the two methods is very close.

We can see from Fig. 3a that the distributions of the Curie surface estimated with the model and aeromagnetic anomaly are essentially consistent. Two uplift zones with relatively shallow Curie surfaces are located from Lijiang-Jianchuan-Baoshan to Tengchong and from Jianchuan-Chuxiong to Kunming-Yuxi. In particular, the shallowest location of the Curie surface in the Tengchong volcanic geothermal region with the most intense new tectonic movement is at $20.8 \mathrm{~km}$. The distribution direction of the Curie surface uplift zone has a corresponding relationship with the deep large fault zone. For example, the uplift zone of the Curie surface is near the LijiangXiaojinhe fault $\left(\mathrm{F}_{3}\right)$, Nujiang fault $\left(\mathrm{F}_{1}\right)$, and Red River fault $\left(\mathrm{F}_{4}\right)$ zones. Previous studies have indicated that these fault zones are relatively deep (Zhang 2013), and they even penetrate the crust to reach the upper mantle and become a pathway for the upwelling of hot material. 

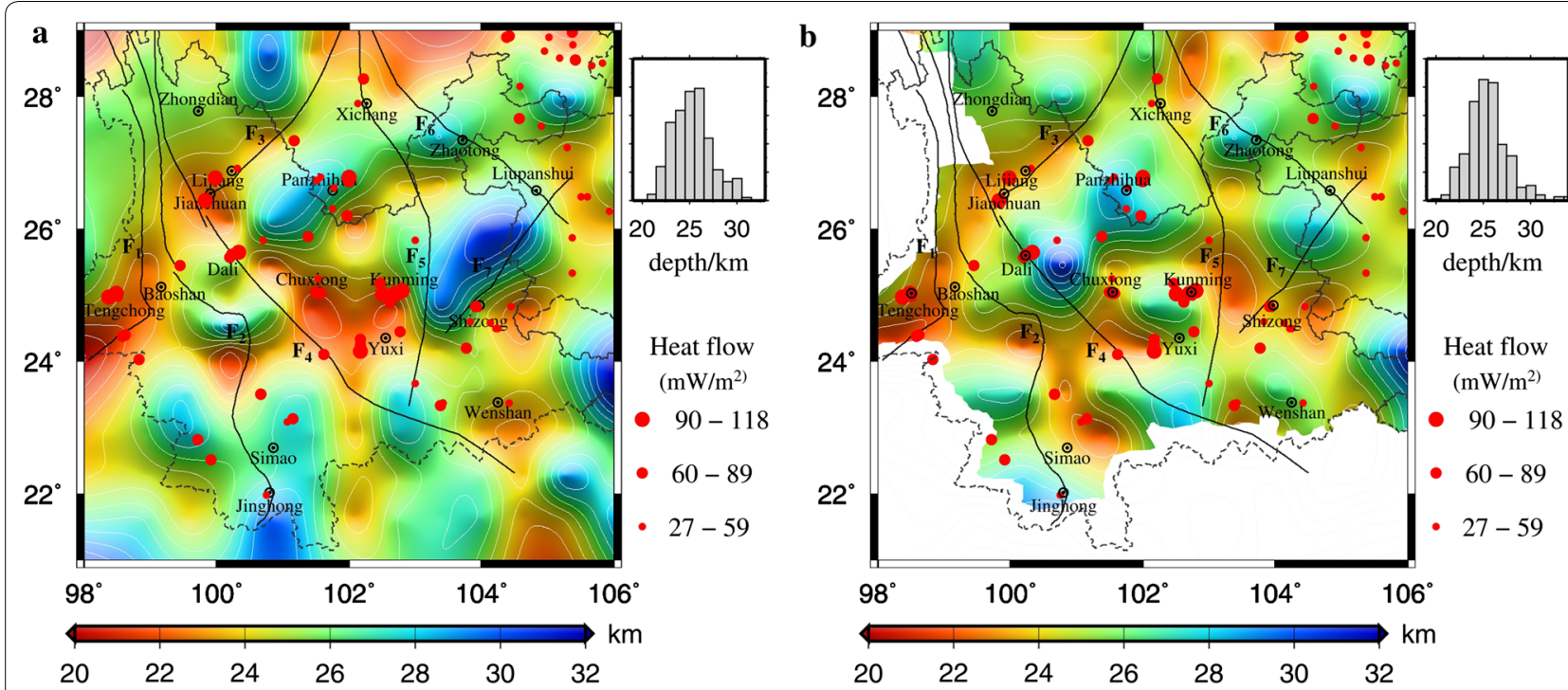

Fig. 3 Depth of the Curie surface. a from NGDC-720 model; $\mathbf{b}$ from aeromagnetic anomaly. Red points are the measurement sites of the surface heat flow

Volcanic activity and earthquakes cause the changes of crustal geomagnetic field (Utada et al. 2011). The Tengchong block is a Cenozoic active volcanic area. Significant earthquakes $\left(M_{\mathrm{s}} \geq 6.0\right)$ have occurred more than once in this area. Therefore, the fluctuations of the Curie surface were caused by changes in the crustal magnetic field of approximately $20 \mathrm{nT}$ beneath the Tengchong block.

\section{Results and discussion}

\section{Curie surface and thermal structure}

\section{Comparison with measured heat flow values}

Since the 1980s, many borehole observations of terrestrial heat flow in the research area have been performed. Based on the collection of terrestrial heat flow data in this area of China (Hu et al. 2000, 2001; Jiang et al. 2016; Wang and Huang 1988; Wang et al. 1990) and the measurement data presented by Yuan et al. (2006), we collected the observation values of heat flow, the geothermal gradient, and thermal conductivity for 97 measurement sites in the research area. The locations of the measurement sites of heat flow are mainly distributed in the regions of Kunming, Dali, Lijiang, and Tengchong (Fig. 3). It is insufficient to accurately determinate the temperature distribution over the study region because the measurement of the heat flow is sparse and uneven. Thus, this limitation prevents us from understanding the lithospheric thermal state in such an important area. Because the magnetic anomalies cover most of the study region, the Curie surface can reflect the characteristics of the transverse change in the thermal structure in the research area and enrich our understanding of the crustal thermal state. On the one hand, it can overcome the problems of the uneven distribution of measurement sites for heat flow and the disturbance of heat flow generated by the water circulation. On the other hand, it can reveal the characteristics of the thermal state in the regions without a heat flow value.

Differences are computed using the Krige method (Oliver 1990) and the polynomial smoothing process for the heat flow and thermal conductivity. The distribution of the surface heat flow and thermal conductivity are shown in Fig. 4. The heat flow value ranges from 20.8 to $118.0 \mathrm{~mW} / \mathrm{m}^{2}$. The average heat flow value is $67.5 \mathrm{~mW} /$ $\mathrm{m}^{2}$, which is higher than the average heat flow value of $65 \mathrm{~mW} / \mathrm{m}^{2}$ for the global continent and higher than the average heat flow value of $63 \mathrm{~mW} / \mathrm{m}^{2}$ for mainland China as a whole (Hu et al. 2001). Because the Tengchong block is a Cenozoic active volcanic area, the highest heat flow $\left(118 \mathrm{~mW} / \mathrm{m}^{2}\right)$ is observed in the area. The low heat flow is observed in the Sichuan Basin, which is located in the northeastern part of our study region. The reason may be that the area is situated in the Sichuan Basin.

The research area has high geothermal characteristics, and the lateral variation in the heat flow distribution is relatively large. The measured heat flow data are meshed for further analysis. Generally, the heat flow is relatively high in the western orogenic zone and exhibits a wavelike decrease from west to east (Xiang and Zhou 2000). The high heat flow region has a banded distribution (Fig. 4a). The Lijiang-Jianchuan-Baoshan-Tengchong and Jianchuan-Dali-Chuxiong-Kunming-Yuxi anomalies in 


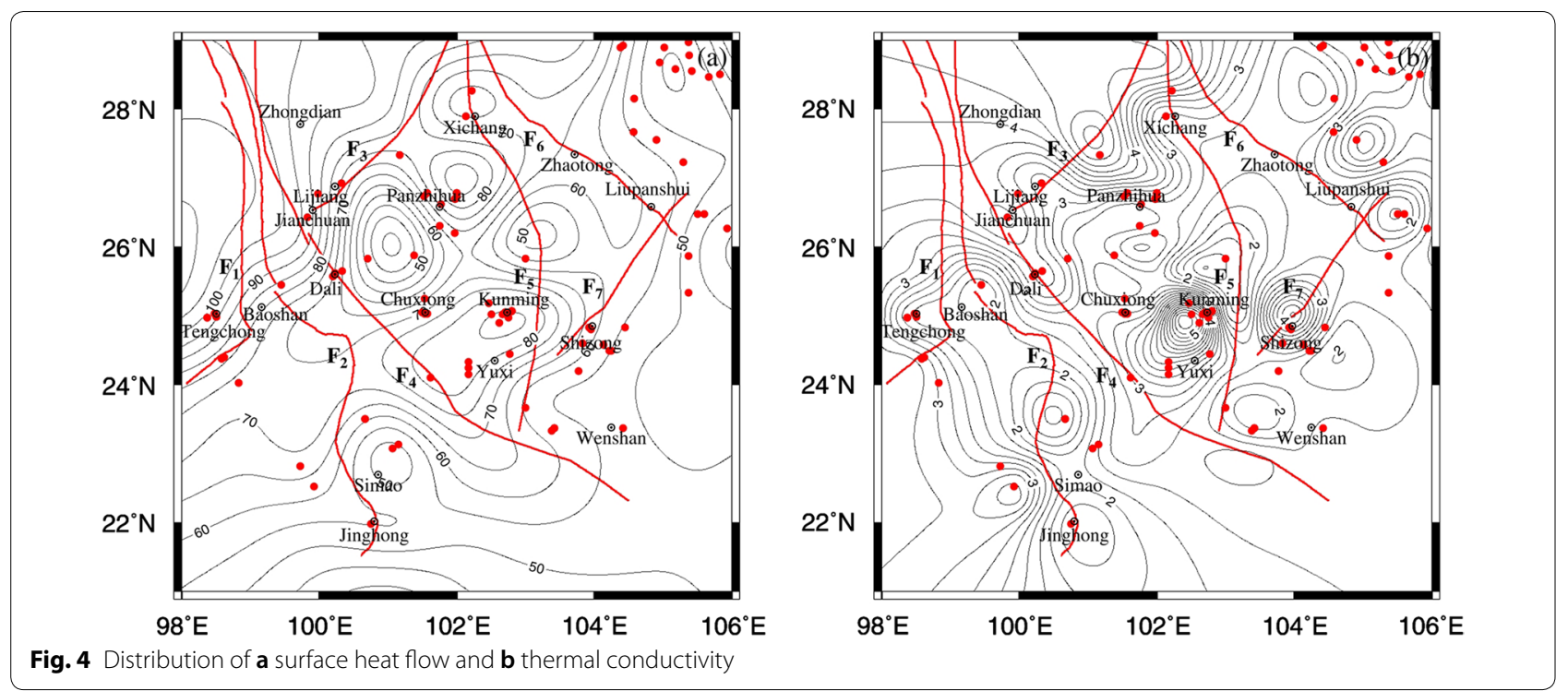

Table 1 Contrast terrestrial heat flow and magnetic anomalies

\begin{tabular}{|c|c|c|c|c|c|c|c|c|}
\hline No. & Name & Longitude ( $\left.{ }^{\circ} \mathrm{E}\right)$ & Latitude ( $\left.{ }^{\circ} \mathrm{N}\right)$ & $q_{s}\left(\mathrm{~mW} / \mathrm{m}^{2}\right)$ & $\Delta F / \mathrm{nT}$ & $\mathrm{CDP} / \mathrm{km}$ & $\begin{array}{l}\text { Crustal } \\
\text { thickness H/km }\end{array}$ & $\begin{array}{l}\text { Velocity } \\
\text { ratio } V p / V s\end{array}$ \\
\hline 1 & Tengchong & 98.48 & 25.03 & 118.0 & 14.0 & 23.6 & 35.7 & 1.81 \\
\hline 2 & Kunming & 102.80 & 25.67 & 112.3 & 11.1 & 23.7 & 44.0 & 1.77 \\
\hline 3 & Jianchuan & 99.83 & 26.43 & 98.5 & -23.9 & 23.9 & 46.1 & 1.82 \\
\hline 4 & Yanyuan & 101.17 & 27.33 & 89.3 & -19.8 & 23.9 & 53.4 & 1.80 \\
\hline 5 & Chuxiong & 100.20 & 25.57 & 82.9 & 8.1 & 24.5 & 41.8 & 1.75 \\
\hline 6 & Dali & 100.33 & 25.65 & 103.4 & 15.6 & 24.7 & 42.5 & 1.74 \\
\hline 7 & Miyi & 102.00 & 26.78 & 90.0 & -3.2 & 24.7 & 49.1 & 1.71 \\
\hline 8 & Eshan & 102.17 & 24.15 & 98.1 & -23.3 & 24.9 & 38.9 & 1.71 \\
\hline
\end{tabular}

the western orogenic zone are two high heat flow zones. The intense tectonic activity causes these deep large fault zones to have high geothermal characteristics. Figure $4 \mathrm{~b}$ shows the distribution of the measured thermal conductivity. We can see that the distribution pattern of the surface heat flow and thermal conductivity does not proportionally change, indicating the complexity of the thermal tectonics in the research area.

Although the distribution of the surface heat flow is not uniform, we can clearly see that the magnitude of the heat flow value is comparable to the undulation of the Curie surface (Figs. 3, 4). To quantitatively compare the relationship between the heat flow and the Curie surface, Table 1 lists the magnetic anomaly, Curie point depth, wave velocity ratio, and crustal thickness value at locations where the heat flow value is greater than $80 \mathrm{~mW} /$ $\mathrm{m}^{2}$ (Deng et al. 2014). In the regions of Tengchong, Kunming, and Jianchuan with high heat flow, the Curie surface is relatively shallow (depth is less than $24 \mathrm{~km}$ ). In the regions of Eastern Yunnan and Simao with low heat flow, the Curie surface is relatively deep. In some regions of the world, there is an obvious inverse correlation between the Curie surface and terrestrial heat flow (Bilim et al. 2016; Saada 2016). In the research area of this paper, the undulation of the Curie surface and the surface heat flow also have a similar inverse correlation, although it is not obvious. This could be caused by the uneven distribution of the heat flow measurement sites.

We extract the Curie point depth at the heat flow measurement sites and plot a scatter diagram for the heat flow and Curie point depth (Fig. 5a). We can see that there is no linear correlation between the Curie point and heat flow, and the corresponding relationship is scattered. However, as the Curie point depth increases, the heat flow decreases gradually. This result indicates that there are many factors that influence the Curie surface and terrestrial heat flow.

A previous study indicated that the orogenic zone and active tectonic belt often exhibit negative magnetic anomalies or weak magnetic anomalies, and the blocks 

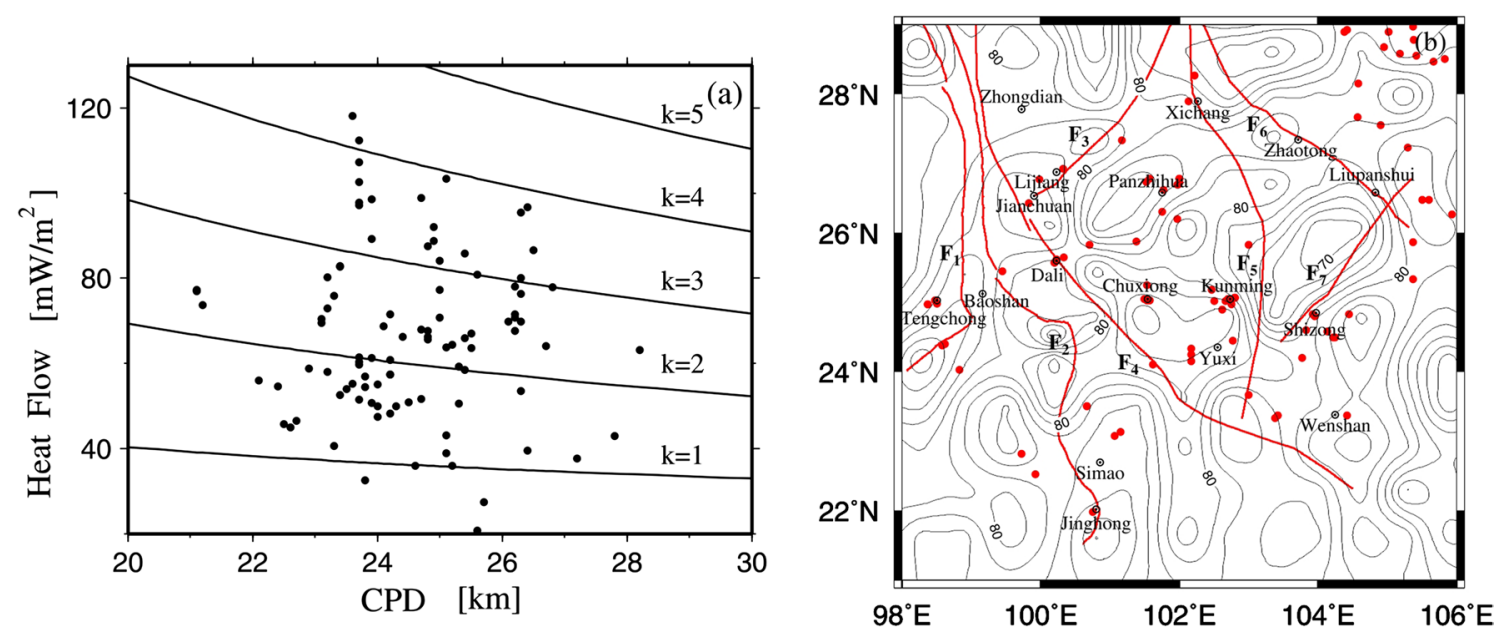

Fig. 5 a Scatter plot of the Curie surface and surface heat flow value, and the curves corresponding to $k=1-5$ in Fig. are the theoretical curves of the heat flow and Curie surface calculated using the 1-D heat conduction model. $\mathbf{b}$ Heat flow distribution at the Curie point depth estimated using the 1-D heat conduction model (coefficient of thermal conductivity $k=2.88$ )

with stable tectonics exhibit positive magnetic anomalies (Xu 2009). The magnetic anomalies in the research area range from -203 to $136 \mathrm{nT}$. We can see from Table 1 that in the regions of Tengchong, Jianchuan, and Kunming, which have Curie surface uplift and relatively high heat flow values, the magnetic anomalies are either negative or in the strong and weak transition zone. These regions are located at the intersection of several major terraces of the Eurasian plate, Indian subcontinent, and Pacific plate, where tectonic activity is strong (Schoenbohm et al. 2006; Wang et al. 2002), forming the nearly north-east-trending Cenozoic orogenic belt. The lithospheric thermal state has been affected and controlled by the tectonic extrusion action on the southeastern margin of the Tibetan Plateau since the Cenozoic period, which could be one reason for the relatively weak magnetic anomalies.

There are many factors that affect the depth of the Curie surface, including the surface heat flow, geothermic gradient, rock heat generation rate, mantle heat flow, fault activity, and physical properties and compositions of rocks (Bilim et al. 2016; Salazar et al. 2017). To further understand the relationship between the surface heat flow $\left(q_{\mathrm{s}}\right)$ and depth of the Curie point $\left(Z_{\mathrm{b}}\right)$, we consider a one-dimensional (1-D) steady-state heat conduction model, in which the Curie surface and heat flow value are inversely correlated (Li et al. 2013; Speranza et al. 2016; Wang and Li 2015). The formula is as follows:

$$
q_{\mathrm{s}}=k \frac{T_{\mathrm{C}}-T_{0}}{Z_{\mathrm{b}}-Z_{0}}+h_{\mathrm{r}}^{2} H_{0} \frac{\mathrm{e}^{-z_{\mathrm{b}} / h_{\mathrm{r}}}-\mathrm{e}^{-z_{0} / h_{\mathrm{r}}}}{Z_{\mathrm{b}}-Z_{0}}+h_{\mathrm{r}} H_{0} \mathrm{e}^{-z_{0} / h_{\mathrm{r}}}
$$

where $q_{\mathrm{s}}$ is the surface heat flow, $Z_{\mathrm{b}}$ is the Curie point depth, $k$ is the coefficient of thermal conductivity (also called the thermal conductivity), $H_{0}$ is the heat generation rate of surface radioactivity, $h_{\mathrm{r}}$ is the thermal characteristic depth $\left(h_{\mathrm{r}}\right.$ is the characteristic drop-off of heat production), $T_{0}$ is the temperature at elevation $Z_{0}$ above the ground surface, and $T_{\mathrm{c}}$ is the Curie temperature. We assume that $T_{0}=10{ }^{\circ} \mathrm{C}$ (note that $10{ }^{\circ} \mathrm{C}$ is the annual average temperature in our study region), $T_{\mathrm{c}}=580^{\circ} \mathrm{C}$ (for the magnetic layer, the Curie temperature $\left(T_{\mathrm{c}}\right)$ within the continental region is approximately $580{ }^{\circ} \mathrm{C}$ ), and $Z_{0}=0$. $H_{0}$ and $h_{\mathrm{r}}$ are taken as $2.0 \mu \mathrm{W} / \mathrm{m}^{3}$ and $10.0 \mathrm{~km}$, respectively (Speranza et al. 2016). The calculated theoretical curves of $q_{\mathrm{s}}-Z_{\mathrm{b}}$ when $k=1-5$, according to Eq. (9), are shown in Fig. 5a (solid line). The heat flow values at all measurement sites are in the range of $k<5$. The thermal conductivity corresponding to the average heat flow value is between the theoretical lines of $k=2.5$ and $3.0 \mathrm{~W} /$ $\left(\mathrm{m}^{\circ} \mathrm{C}\right)$. The average thermal conductivity value measured by surface drilling is $2.88 \mathrm{~W} /\left(\mathrm{m}^{\circ} \mathrm{C}\right)$ (Table 2), which is between the theoretical lines of the 1-D heat conduction model. Prior studies have indicated that the average thermal conductivity in different areas is different, but it generally ranges from 2.0 to $3.0 \mathrm{~W} /\left(\mathrm{m}^{\circ} \mathrm{C}\right)$. For example, the average thermal conductivity is $2.5 \mathrm{~W} /\left(\mathrm{m}^{\circ} \mathrm{C}\right)$ in Southeast Asia (Tanaka et al. 1999), $3.0 \mathrm{~W} /\left(\mathrm{m}^{\circ} \mathrm{C}\right)$ in the North American continent (Wang and Li 2015), and $2.18 \mathrm{~W} /\left(\mathrm{m}^{\circ} \mathrm{C}\right)$ in the Po Plain (northern Italy) (Speranza et al. 2016).

By using Eq. (7), the distribution of the terrestrial heat flow calculated using the average coefficient of thermal conductivity $k=2.88 \mathrm{~W} /\left(\mathrm{m}^{\circ} \mathrm{C}\right)$, as shown in Fig. $5 \mathrm{~b}$. In 
Table 2 Measured data of heat flow $\left(q_{s}\right)$ and the thermal conductivity $(K)$

\begin{tabular}{|c|c|c|c|c|}
\hline No. & Longitude ( $\left.{ }^{\circ} \mathrm{E}\right)$ & Latitude ( $\left.{ }^{\circ} \mathrm{N}\right)$ & $q_{s}\left(\mathrm{~mW} / \mathrm{m}^{2}\right)$ & $K \mathrm{~W} /\left(\mathrm{m}^{\circ} \mathrm{C}\right)$ \\
\hline 1 & 98.48 & 25.03 & 118.1 & 2.99 \\
\hline 2 & 102.80 & 25.07 & 112.3 & 2.06 \\
\hline 3 & 102.80 & 25.07 & 107.3 & 4.43 \\
\hline 4 & 100.33 & 25.65 & 103.4 & 4.60 \\
\hline 5 & 102.80 & 25.07 & 102.6 & 4.43 \\
\hline 6 & 102.00 & 26.78 & 98.9 & 3.62 \\
\hline 7 & 99.83 & 26.43 & 98.5 & 4.15 \\
\hline 8 & 102.80 & 25.07 & 97.7 & 6.16 \\
\hline 9 & 99.98 & 26.77 & 97.1 & 3.36 \\
\hline 10 & 102.50 & 25.02 & 96.7 & 5.73 \\
\hline 11 & 102.70 & 25.03 & 95.5 & 2.08 \\
\hline 12 & 102.17 & 24.15 & 92.1 & 3.38 \\
\hline 13 & 101.17 & 27.33 & 89.3 & 5.23 \\
\hline 14 & 98.50 & 24.98 & 88.8 & 1.71 \\
\hline 15 & 100.23 & 25.62 & 87.5 & 3.61 \\
\hline 16 & 102.67 & 25.02 & 86.6 & 2.29 \\
\hline 17 & 102.17 & 24.25 & 85.8 & 4.27 \\
\hline 18 & 102.00 & 26.78 & 84.1 & 3.17 \\
\hline 19 & 101.57 & 25.03 & 82.9 & 2.48 \\
\hline 20 & 101.57 & 25.03 & 82.7 & 3.42 \\
\hline 21 & 102.47 & 25.18 & 80.9 & 2.38 \\
\hline 22 & 101.50 & 25.05 & 80.2 & 3.09 \\
\hline 23 & 102.72 & 25.03 & 80.1 & 6.16 \\
\hline 24 & 102.72 & 25.03 & 78.1 & 3.15 \\
\hline 25 & 102.62 & 24.90 & 77.9 & 4.26 \\
\hline 26 & 98.62 & 24.40 & 77.2 & 3.14 \\
\hline 27 & 98.58 & 24.38 & 76.9 & 3.39 \\
\hline 28 & 102.70 & 25.05 & 76.3 & 2.29 \\
\hline 29 & 102.22 & 28.27 & 75.9 & 4.35 \\
\hline 30 & 98.58 & 24.38 & 73.7 & 3.27 \\
\hline 31 & 101.53 & 25.03 & 72.9 & 2.71 \\
\hline 32 & 102.70 & 25.05 & 71.5 & 2.43 \\
\hline 33 & 99.45 & 25.45 & 70.8 & 1.71 \\
\hline 34 & 102.73 & 25.03 & 70.8 & 2.41 \\
\hline 35 & 102.70 & 25.05 & 69.8 & 2.41 \\
\hline 36 & 102.73 & 25.03 & 69.8 & 2.41 \\
\hline 37 & 101.53 & 25.03 & 69.5 & 2.40 \\
\hline 38 & 103.38 & 23.33 & 68.8 & 2.93 \\
\hline 39 & 101.62 & 24.10 & 68.0 & 2.98 \\
\hline 40 & 102.73 & 25.03 & 67.7 & 2.66 \\
\hline 41 & 101.38 & 25.88 & 67.6 & 3.07 \\
\hline 42 & 102.17 & 24.33 & 67.0 & 4.18 \\
\hline 43 & 100.20 & 25.57 & 66.3 & 3.41 \\
\hline 44 & 103.92 & 24.83 & 66.2 & 4.38 \\
\hline 45 & 99.72 & 22.82 & 66.0 & 2.62 \\
\hline 46 & 100.20 & 25.57 & 65.6 & 3.41 \\
\hline 47 & 102.00 & 26.72 & 64.4 & 2.59 \\
\hline 48 & 101.97 & 26.20 & 64.1 & 3.35 \\
\hline 49 & 101.15 & 23.13 & 63.2 & 2.93 \\
\hline
\end{tabular}

Table 2 (continued)

No. Longitude $\left({ }^{\circ} \mathrm{E}\right)$

\begin{tabular}{rrrll}
\hline 50 & 105.42 & 28.55 & 61.5 & 2.93 \\
51 & 99.92 & 22.52 & 61.3 & 3.72 \\
52 & 102.00 & 26.72 & 59.3 & 2.99 \\
53 & 101.97 & 26.70 & 58.5 & 2.63
\end{tabular}

$54 \quad 105.38$

28.78

23.37

26.92

27.90

28.58

26.70

24.80

23.08

28.90

26.78

21.98

26.73

28.68

26.62

27.67

24.20

24.60

24.58

23.37

26.48

24.83

23.67

27.23

25.25

27.55

28.47

25.33

28.50

25.83

24.50

24.50

26.27

23.50

23.50

23.37

24.97

25.83

26.30

25.87

26.48

28.92

28.90

28.15

28.97
2.84

$\begin{array}{ll}58.1 & 2.84 \\ 57.4 & /\end{array}$

$55.3 \quad 2.79$

$55.1 \quad 2.11$

$51.5 \quad 3.00$

$50.6 \quad 2.42$

$48.3 \quad 6.67$

$43.0 \quad 2.33$

$40.7 \quad 2.85$

$39.0 \quad 3.53$

$37.7 \quad 1.43$

$36.0 \quad 2.32$

$32.6 \quad 3.00$

$27.4 \quad 2.34$

$63.6 \quad 2.93$

$60.3 \quad 2.50$

$59.8 \quad 2.50$

$58.8 \quad 2.30$

$57.4 \quad 1.70$

$56.9 \quad 1.67$

$56.0 \quad 2.30$

$54.6 \quad 1.88$

$54.0 \quad 3.14$

$52.6 \quad 1.67$

$51.6 \quad 4.19$

$50.8 \quad 2.50$

$49.9 \quad 2.50$

$\begin{array}{ll}47.5 & 3.77\end{array}$

$46.5 \quad 1.47$

$45.8 \quad 2.09$

$45.0 \quad 2.71$

$36.0 \quad 2.93$

$77.3 \quad 1.07$

$\begin{array}{ll}63.8 & 1.07\end{array}$

$50.9 \quad 2.50$

$53.5 \quad 2.50$

$20.8 \quad 2.09$

$39.5 \quad 2.50$

$49.9 \quad 2.50$

$54.4 \quad 1.67$

$60.9 \quad 2.93$

$71.6 \quad 2.09$

$43.2 \quad 2.09$

$\begin{array}{ll}70.5 & 2.09\end{array}$ 

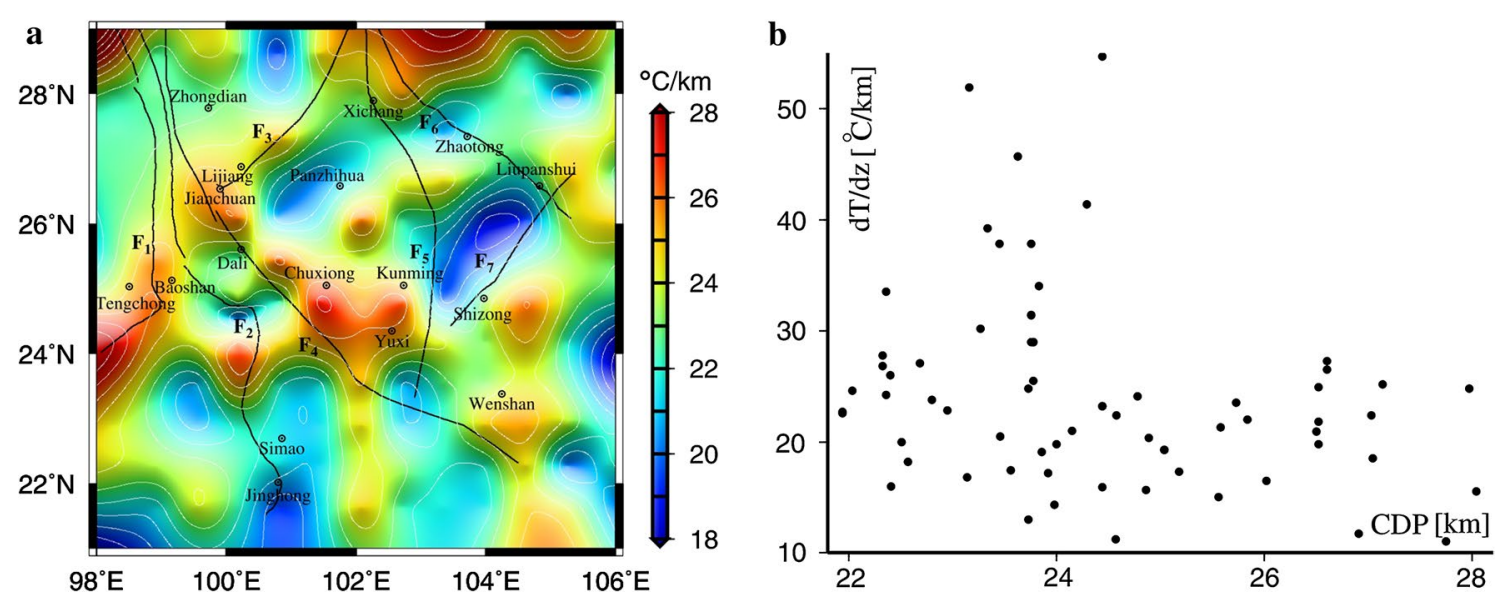

Fig. 6 a Geothermal gradient retrieved from the Curie surface, and $\mathbf{b}$ distributed scatter plot for the measured geothermal gradient and depth of the Curie surface

comparison with the heat flow measured on the ground surface (Fig. 4a), the distribution pattern is essentially consistent, while only the values are different. The first possible reason for this difference is that the observation data are not sufficiently uniform. The second possible reason is that there are many influencing factors, and the actual coefficients of thermal conductivity in different regions are largely different (Fig. 4b). We use a 1-D heat conduction model and predict the average coefficient of thermal conductivity. Although this calculation is not sufficiently objective, it still can reflect the trend in the changes. The corresponding relationship between $q_{\mathrm{s}}$ and $Z_{b}$ in the research area is scattered, which indicates that the 1-D thermal conductivity model cannot completely explain the relationship between the Curie surface and surface heat flow. The relationship likely needs to include other thermal conversion mechanisms, such as thermal convection, to explain the scattering relationship between the heat flow and Curie surface (Tanaka et al. 1999).

\section{Comparison between the Curie surface and geothermal gradient}

According to the Curie-Weiss Law, we can use the depth of the Curie surface estimated by the magnetic anomaly to calculate the heat flow gradient $\Delta T=T / Z_{\mathrm{b}}$ (Maden 2010; Saibi et al. 2015), where $\Delta T$ is the geothermal gradient and $T$ is the Curie point temperature. We assume the temperature of the Curie point to be $T=580{ }^{\circ} \mathrm{C}$ to obtain the geothermal gradient in the research area (Fig. 6a). We can see that Lijiang-Jianchuan-BaoshanTengchong and Jianchuan-Chuxiong-Kunming-Yuxi are two obvious geothermal gradient zones, similar to that shown in Fig. 4a. This result indicates that applying the
Curie surface retrieved from a magnetic anomaly to infer the distribution of the geothermal gradient can provide the basic trend of the crustal thermal structure.

We extract the Curie point depth at the location of a measured geothermal gradient and generate a scatter plot for the geothermal gradient and depth of the Curie surface (Fig. 6b). We can see that there is no simple linear relationship between them. However, as the depth of the Curie surface increases, there is a significant change in the geothermal gradient. When the depth of the Curie surface is greater than $25 \mathrm{~km}$, the geothermal gradient is smaller than or near the average $\left(26.8^{\circ} \mathrm{C} / \mathrm{km}\right)$. In the region where the Curie point depth is smaller than $25 \mathrm{~km}$, the variation range of the geothermal gradient is relatively large, which is likely because more factors influence the geothermal gradient in the shallow-layer medium than in the deep-layer medium.

\section{Curie surface and crustal structures Curie surface and Moho surface}

The depth of the Curie surface is the lower interface of the crustal magnetic rock and reflects the thermal state of the lithosphere. The Moho surface mainly reflects the discontinuous interface of the lithospheric density, which can be retrieved from a seismic wave. Based on the equivalent source hypothesis, Langston (1979) separated the receiver function from the long-period teleseismic body wave. Owens et al. (1984) extended it to broadband recording and obtained the broadband receiver function. The receiver function is the time series of the converted wave arrival time from the velocity discontinuity in the receiving area below the station. Because of the easy extraction, stability, and high resolution of the receiver function, this method has been widely used to study the 

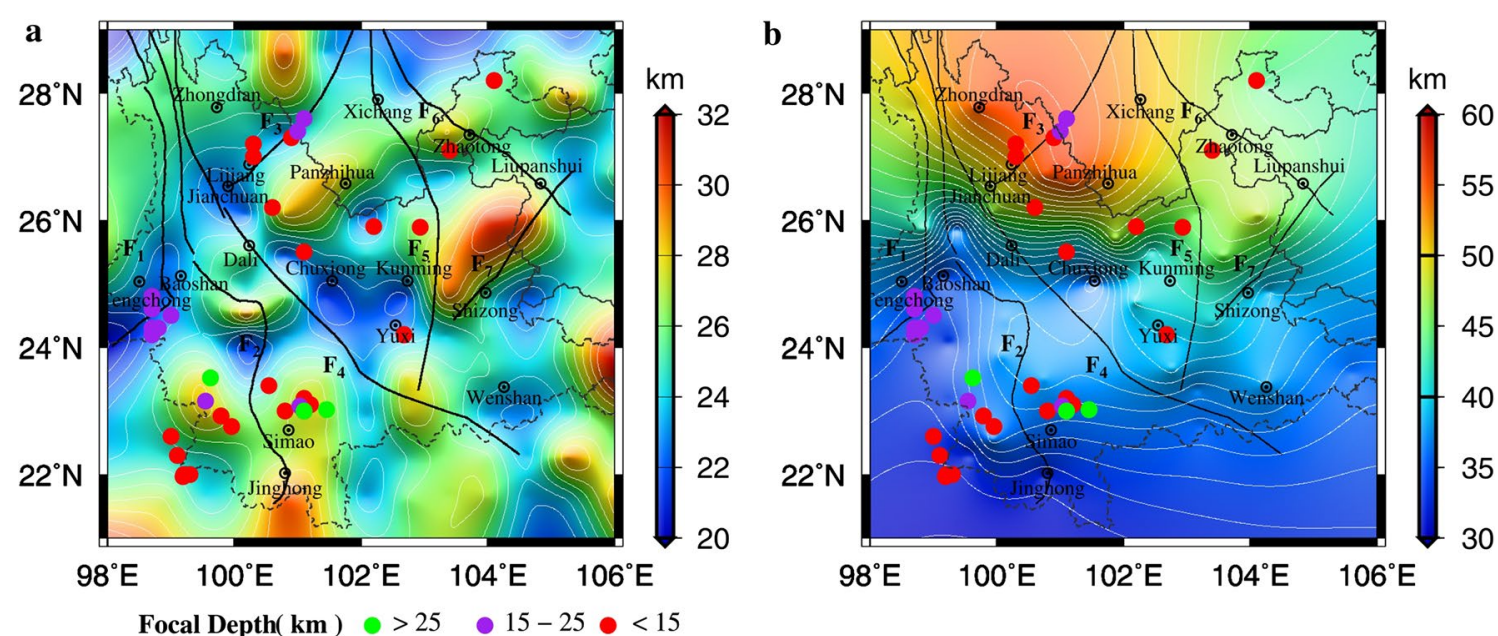

Fig. 7 Depth of the Curie surface (a) and Moho surface (b) in the research area, as well as the focal depths of the earthquakes with $M_{s} \geq 6.0$ in the study region (b is modified from Deng et al. (2014))

velocity structure of the crust and upper mantle (Xu et al. 2013; Zhang et al. 2015). Based on the far seismic data $\left(M_{\mathrm{s}} \geq 6.0\right.$, during July 2007 to July 2008$)$ derived from the 46 broadband seismic stations in our study region, Deng et al. (2014) extracted the P-wave receiver function beneath the stations and calculated the depth of the Moho surface. The result is shown in Fig. 7b. We can see that the change in the depth of the Moho surface is relatively large. It changes from $30 \mathrm{~km}$ in the southwest region to $55 \mathrm{~km}$ in the northwest region, and the magnitude of the change exceeds $25 \mathrm{~km}$ (Kan et al. 1986). Comparing the Curie surface and Moho surface (Fig. 7), it can see that the depth of the Curie surface is less than that of the Moho surface.

To compare the relationship between the Curie and Moho surfaces and the distribution of earthquakes, the earthquakes $\left(M_{\mathrm{s}} \geq 6.0\right)$ in the study area since 1970 are plotted in Fig. 7a, b. The seismic data are from the China Seismic Network Center (CSN) earthquake catalog (http://data.earthquake.cn). The accuracy of the earthquake locations is less than $10 \mathrm{~km}$. The focal depths of the earthquakes vary from 5 to $33 \mathrm{~km}$, with an average of $16 \mathrm{~km}$. Compared with the Curie and Moho depths (Fig. 7), the distribution of earthquakes is mainly located in the area of the transitional cascade zone of the Curie surface, and the focal depth is less than the Moho depth. This phenomenon can be observed in the Tengchong block, Middle Yunnan block, and Lijiang-Xiaojinhe fault $\left(\mathrm{F}_{3}\right)$ zone. The crust's brittle-ductile transition temperature is generally $300-600{ }^{\circ} \mathrm{C}$ (i.e., $5-25 \mathrm{~km}$ depth) (Zhao et al. 2011). The upper, middle, and lower crusts in an area with strong earthquakes are in brittle, brittle-ductile, and ductile states, respectively (Hao et al. 1982; Zhou et al. 1997). Under the effect of regional stress, the lower crust cannot withstand very high differential stress and cannot store very high elastic strain. As a result, there are few strong earthquakes in the lower crust. In contrast, the lower crust transfers tectonic stress to the brittle rock masses in the middle and upper crust, concentrating the differential stress and accumulating strain energy. Therefore, the strong earthquakes in southeastern Tibet mainly occurred in the Curie surface uplift areas in the middle and upper crust.

Figure 8 shows the distribution of the difference between the depth of the Moho surface and the depth of the Curie surface. We can see that the difference between the Curie surface and Moho surface is less than $10 \mathrm{~km}$ in the region south of approximately $25^{\circ}$ latitude, whereas the difference is relatively large in the northern region, and the maximum exceeds $30 \mathrm{~km}$. These results are similar to the results in the Alps, where the depth of the Curie surface is shallower than the depth of the Moho surface by $20-40 \mathrm{~km}$ (Speranza et al. 2016). Studies on the relationship between the Curie surface and Moho surface have indicated that the depth of the Curie surface in a marine area is greater than that of the Moho surface. It is different in a continental area. In some areas, the depth of the Curie surface is smaller than that of the Moho surface, while their variation trend in some areas is consistent (Speranza et al. 2016; Wang and Li 2015; Wasilewski and Mayhew 1992). These results indicate that the depths of the Curie surface and Moho surface are related to the regional structural environment and that there is no unified relationship between them.

The Curie surface is not a fixed geological interface, although it appears to have connections with some 


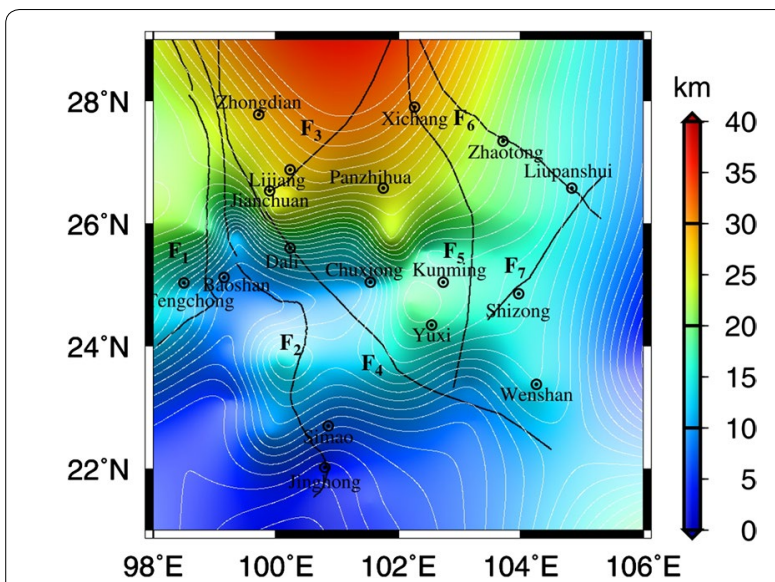

Fig. 8 Differences in the depths of the Curie surface and Moho surface. The positive value indicate that the depth of Curie surface less the depth of Moho surface

interfaces. It is generally located on the crustal seismic wave velocity discontinuities. The calculation results in many regions have indicated that the Curie surface is mostly located near the Conrad discontinuity, while it is sometimes in the mantle. Artificial seismic sounding experiments indicate that in most seismograms of the Yunnan area, the reflection seismic phase Pc inside the crust is relatively clear, and the depth of the corresponding discontinuity surface (Conrad interface) varies in the range of 20-30 km (Wang et al. 2002). Therefore, the depth of the Curie surface in the research area is comparable to the Conrad interface, and their relationship needs to be further studied.

According to Table 1, the latitude of the Tengchong, Dali, Chuxiong, and Kunming regions with relatively large heat flow values in the research area is near $25^{\circ} \mathrm{N}$. To further understand the characteristics of the transverse variation in the Curie surface, terrestrial heat flow, and the depth of the Moho surface, we plot a cross-section of the magnetic anomalies, terrestrial heat flow, and depths of the Curie surface and Moho surface on the $25^{\circ}$ $\mathrm{N}$ profile (Fig. 9). We can see that the high-value region of terrestrial heat flow is the Tengchong area and Kunming area of western Yunnan. A wave-like decrease occurs from west to east, and the change in the heat flow is close to the variation trend of the magnetic anomalies. The Curie surface and surface heat flow are partially inversely correlated. For instance, there is an obvious correlation present to the west of $102^{\circ} \mathrm{E}$, although the correlation is not obvious to the east. There is no corresponding relationship between the Curie surface and change in crustal thickness. Studies in some other areas have indicated that there is an obvious correlation between the Curie surface and crustal thickness (Arnaiz-Rodríguez et al. 2013; Wasilewski and Mayhew 1992). These results together indicate that the corresponding relationship between

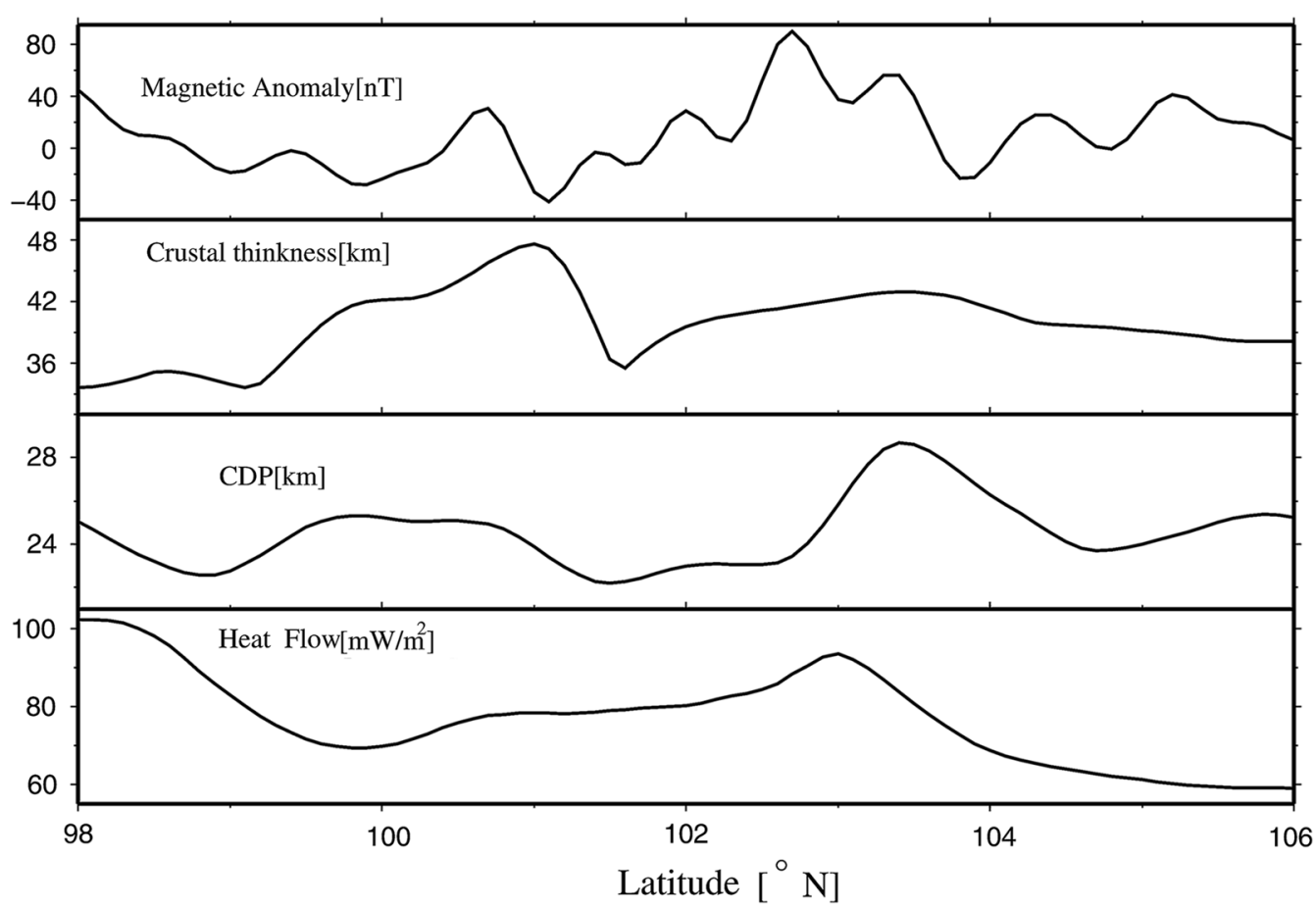

Fig. 9 Magnetic anomaly, crustal thickness, depth of the Curie surface, and terrestrial heat flow on the cross section at $25^{\circ} \mathrm{N}$ 
them is controlled by regional tectonics, and it cannot be explained by a unified pattern.

There is a close connection between the undulation of the Curie surface and crust-mantle heat flow. According to the relationship between the seismic wave velocity $v_{\mathrm{P}}$ and heat generation rate (Zhou et al. 1997), measurement values of the terrestrial heat flow and data of the radioactive heat generation rate, Wang et al. (1990) studied the crust-mantle thermal state of the Yunnan area. The results indicated that the Tengchong block, Yanyuan Lijiang continental margin depression (Lijiang- Jianchuan area), and Kangdian ancient uplift (Kunming area) are three high geothermal tectonic units. Their crust-mantle heat flow ratios are 1.52, 1.04, and 1.23, respectively, and the corresponding temperatures of the Moho surface are $1088^{\circ} \mathrm{C}, 1015^{\circ} \mathrm{C}$, and $945^{\circ} \mathrm{C}$. The crust-mantle heat flow ratio and temperature of these Moho surfaces are much larger than in other regions. These regions are the Curie surface uplift regions in this paper.

\section{Curie surface and wave velocity ratio anomalies}

The corresponding relationship between the seismic wave velocity $V \mathrm{p}$ anomalies and the undulation of the Curie surface has been confirmed in some regions (Bilim et al. 2016; Speranza et al. 2016). If there is a fluid or melt present inside the crust, the crustal material is subject to partial melting or is located in a shatter belt, which could speed up the attenuation velocity of the seismic wave and cause the wave velocity ratio to be higher than in the surrounding areas. The crust in the research area is mainly a low-velocity layer, and the change in the wave velocity ratio is relatively large. A low-velocity anomaly has stratified and partitioned features (Wang et al. 2002; Xu et al. 2013). In this paper, we discuss the relationship of the wave velocity ratio with the Curie surface of the crust and crustal heat flow.

In the research area, many scholars have used the receiver function method to study the crustal wave velocity ratio $(V \mathrm{p} / V \mathrm{~s})$ and Poisson's ratio (Deng et al. 2014; Zha and Lei 2013; Zhang et al. 2015). Although different values of $V \mathrm{p} / V \mathrm{~s}$ have been obtained by different researchers, the variation trends are consistent. The wave velocity ratio data given by Deng et al. (2014) are interpolated to obtain the distribution of the average crustal wave velocity ratio $(V \mathrm{p} / V \mathrm{~s})$ in Yunnan Province and its adjacent areas (Fig. 10). By comparing the crustal wave velocity ratio and Curie surface (Figs. 3, 10), we can see that the low-velocity anomaly region and the distribution of the Curie surface are comparable in some regions. In the adjacent regions of Xichang, Jianchuan, Tengchong, and Chuxiong with relatively high wave velocity ratios, the Curie surface is relatively shallow. In the region to the east of the

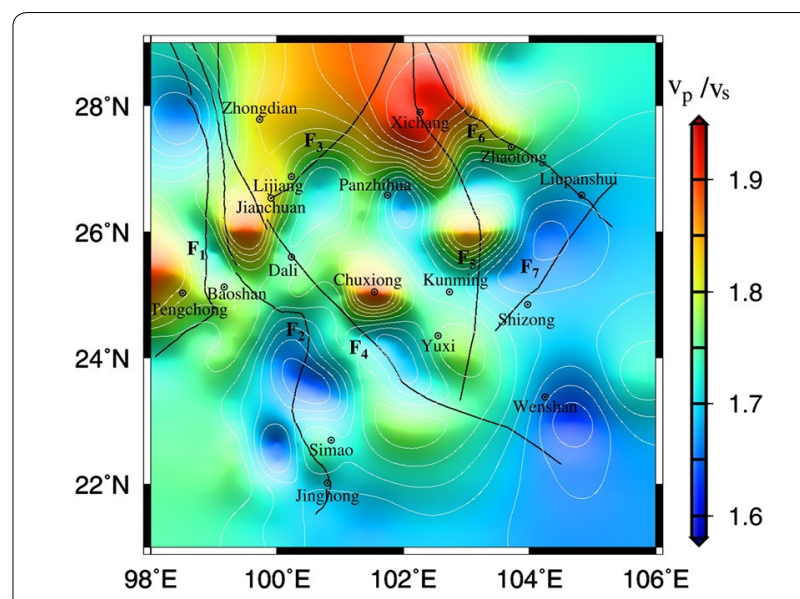

Fig. 10 Distribution of the crustal wave velocity ratio in the research area

Xiaojiang fault $\left(\mathrm{F}_{5}\right)$, to the west of the Red River fault $\left(\mathrm{F}_{4}\right)$, and near the Lancangjiang fault $\left(\mathrm{F}_{2}\right)$ where the wave velocity ratio is relatively low, the Curie surface is relatively deep.

The wave velocity ratio in the research area is distributed in the range of 1.6-1.95, and the average is 1.74 . Table 1 lists the wave velocity ratio values at the measurement sites with relatively high terrestrial heat flow values. By comparing Fig. 10 and Table 1, we can see that the wave velocity ratios at the measurement sites with high heat flow are not extremely large, and the extremely large values are instead located in the strong and weak transition zone of the high wave velocity ratio anomalous zone. This feature is consistent with the results for places in the North Euboean Gulf, Greece, the Alps and Po Plain (northern Italy), and western Turkey along the coastline of the Mediterranean (Bilim et al. 2016; Speranza et al. 2016). The relatively high Vp/ Vs values likely imply an enhancement in the magnesium-iron content in the material composition of the lower crust, and its formation and evolution process could be related to the activity of the mantle material rich in magnesium-iron (Xu et al. 2005). Another possible explanation is that the high wave velocity ratio anomalies are likely caused by the partial melting of the lower crust due to the high temperature of the top of the upper mantle (Li et al. 2009).

We can see from Fig. 10 that the region near Xichang has a relatively large wave velocity ratio. Deep geophysical exploration indicates that the area between Xichang and Panzhihua was once considered to be an ancient rift. Although there is still a dispute regarding the existence of an ancient rift valley, the low wave velocity, low resistivity, and high heat flow in this region are objective facts (Teng 1994). The intersecting fault activities and the factors of rift tension, fluid intrusion, and 
deposition filling are all reasons for the generation of this low-velocity anomaly inside the crust. These facts and the distribution of Cenozoic alkaline magmatic rock and rare metals all reflect the tectonic characteristics of the heat flow channels for the crust-mantle thermal exchange (Xu et al. 2013).

\section{Curie surface and crustal high-conductivity layer}

Over the past 30 years, many scholars have successively developed multiple telluric electromagnetic sounding profiles in the research area to study the geodynamic mechanism and tectonic environment for strong earthquakes in Yunnan Province and its adjacent area (Bai et al. 2010; Li et al. 2014; Shen et al. 2015; Sun et al. 1989; Wang et al. 2017). The results indicate that there is general development of a high-conductivity layer (namely, a low-resistance layer) in the crust of the research area, and its depth is roughly equivalent to the low-velocity layer in the crust. The depth of burial and thickness are slightly different for the low-resistance layers of different blocks. For instance, in the Tengchong block, Jianchuan-Eryuan, and the Yuxi-Kunming area located between the Xiaojiang fault $\left(\mathrm{F}_{5}\right)$ and the Red River fault $\left(\mathrm{F}_{4}\right)$, the thickness of the high-conductivity layer in the middle and lower crust is approximately $10 \mathrm{~km}$, and the depth of the burial is slightly different at different places (Chang et al. 2015; Yu et al. 2017). In particular, the high-conductivity layer with an underground buried depth of $3-20 \mathrm{~km}$ and a thickness of 10-17 km inside the crust of the Tengchong block could be a reflection of the deep magmatic capsule. Based on a comparison with the depth of the Curie surface (Fig. 3), the Curie surface is in the high-conductivity layer, and the correlation between them needs to be further studied.

Another feature of the electrical structure in the research area is that the upper-mantle high-conductivity layer is present in some regions. It is generally believed that the upper-mantle high-conductivity layer is the consequence of partial melting, and its depth of burial has some connection to the thermal state and activity of the lithosphere (Sun et al. 1989). According to existing data, there are three upper-mantle uplift zones present in the research area: The first zone is the upper-mantle high-conductivity layer uplift zone with the Tengchong volcanic zone as the center, whose central burial depth is approximately $60 \mathrm{~km}$. The second zone is the uplift zone with Jianchuan-Heqing as the center, and the depth of burial for the upper-mantle high-conductivity layer is approximately $70 \mathrm{~km}$ and is gently inclined to all areas around it. The third zone is the Panxi rift region (Xichang area in Fig. 10); the depth of burial for the upper-mantle high-conductivity layer in the rift zone is $80-90 \mathrm{~km}$, and it gradually increases toward the east and west side to $100-140 \mathrm{~km}$. The three regions are consistent with the Curie surface uplift zone (Fig. 3). In general, the uplift of the upper-mantle high-conductivity layer and Curie surface uplift zone mutually corroborate each other, which means that the modern crustal tectonic movement has been intense in these regions.

The telluric electromagnetic sounding of Bai et al. (2010) in the eastern Himalayan tectonic junction and surrounding areas determined that two enormous lowresistivity anomaly zones of the middle and lower crusts are present on the Tibetan Plateau. The theoretical calculation suggests that these zones are two weak mass flow channels of the middle and lower crust. One extends eastward from the Lhasa block along the Yarlung Zangbo suture zone, surrounds the eastern Himalayan tectonic junction, then turns south, and finally passes through the Tengchong volcano; the other extends eastward from the Qiangtang terrace along the Jinshajiang fault zone and Xianshuihe fault zone, turns south on the western margin of the Sichuan Basin, and eventually passes through the rhomboid block between the Xiaojiang fault $\left(\mathrm{F}_{5}\right)$ and Red River fault $\left(\mathrm{F}_{4}\right)$.

According to the distribution of the magnetic anomaly and characteristics of the heading direction (Fig. 2), the weak magnetic field or negative magnetic anomaly of the Cenozoic orogenic belt in western Sichuan and Sanjiang is approximately an arc distribution that extends all the way to the Tengchong area, and it corresponds to the first mass flow channel. However, through the mass flow channel between the Xiaojiang fault and Red River fault $\left(\mathrm{F}_{4}\right)$ zone, the distribution of the magnetic anomaly on the ground surface has mainly a clump shape but does not show the abnormal characteristics related to the second mass flow channel. From the perspective of the Curie surface (Fig. 3) and terrestrial heat flow (Fig. 5), the Curie surface uplift zone of the Yunnan Province and its adjacent area is mainly in the LijiangJianchuan-Baoshan-Tengchong zone, which is the same as the heading direction of the weak magnetic anomaly. This is essentially consistent with the first mass flow channel given by the telluric electromagnetic sounding. However, the other Curie surface uplift zone is along the northern side of the Red River fault $\left(\mathrm{F}_{4}\right)$ zone and south of the rhomboid (Middle Yunnan) block, roughly in the Jianchuan-Dali-Kunming-Yuxi zone, which is considerably different from the second mass flow channel.

\section{Conclusions}

The distribution of magnetic anomalies has obvious regional characteristics. The magnetic anomalies in the Sanjiang and western Yunnan orogenic belts to the west of the Lijiang-Xiaojinhe $\left(\mathrm{F}_{3}\right)$ and Red River fault $\left(\mathrm{F}_{4}\right)$ zones are relatively weak. The anomalies of the rhomboid 
block are relatively strong, and there is a clear positivenegative magnetic anomaly zone along the Red River fault $\left(\mathrm{F}_{4}\right)$ zone. Lijiang-Jianchuan-Baoshan-Tengchong and Jianchuan-Dali-Chuxiong-Kunming are two Curie surface uplift zones, and the heat flow is relatively high. As a deep fault, the Red River fault $\left(\mathrm{F}_{4}\right)$ zone may penetrate the crust to reach the upper mantle and become a channel for the upwelling of thermal substance. Thus, beneath the fault, the Curie surface is an uplift zone. The Curie surface is approximately inversely correlated with the magnitude of the heat flow value.

The Curie surface is above the Moho surface in the study region. The Curie surface uplift zone is consistent with a crustal high-conductivity layer, and it is also partially in agreement with the eastern mass flow channel of the Tibetan Plateau. There is a correlation between the Curie surface and crustal wave velocity ratio. The deep Curie surface corresponds to the high crustal wave velocity ratio, while the shallow Curie surface corresponds to the low wave velocity ratio.

The Curie surface calculated using the magnetic anomaly covers most of the research area, and it can reflect the characteristics of the transverse changes in the thermal structure of the research area and enrich or understanding of the crustal thermal state, especially in areas without heat flow information.

\section{Abbreviations \\ CHAMP: CHAllenging Minisatellite Payload; NOAA: National Oceanic and Atmospheric Administration.}

\section{Acknowledgements}

It is gratefully acknowledged that NOAA provided the magnetic data.

\section{Authors' contributions}

LMW and CHB participated in acquisition of magnetic and heat flow data. LMW processed the obtained data. GFK and GMG drafted the manuscript. LMW, GFK, CHB, and GMG contributed to the planning of this study and interpretation of the data. All authors read and approved the final manuscript.

\section{Funding}

This study was sponsored by the National Science Foundation of China under Grant 41864003 and 41664004

\section{Availability of data and materials}

The magnetic anomaly data were provided by National Oceanic and Atmospheric Administration and China National Land and Resources Aeronautical Geophysical Exploration Remote Sensing Center, respectively. We are deeply grateful to the Editor, Associate Editor and two anonymous reviewers for their insightful comments and constructive suggestions, which helped improve this paper. The NGDC-720 model is available on https://geomag.us/models/ ngdc720.html.

\section{Ethics approval and consent to participate}

$$
\text { Not applicable. }
$$

\section{Consent for publication}

Not applicable.

\section{Competing interests}

The authors declare that they have no competing interests.
Received: 5 January 2019 Accepted: 23 July 2019

Published online: 02 August 2019

\section{References}

Abramova LM, Abramova DY, Frunze AK (2013) Lithospheric magnetic anomalies in southeast Asia from CHAMP data. Phys Solid Earth 49:50-58

Arkani-Hamed J (2007) Differential reduction to the pole: revisited. Geophysics 72(1):13-20

Arnaiz-Rodríguez MS, Orihuela N (2013) Curie point depth in Venezuela and the Eastern Caribbean. Tectonophysics 590:38-51

Bai DH, Unsworth MJ, Meju MA, Ma XB, Teng JW, Kong XR, Sun Y, Sun J, Wang LF, Jiang CS, Zhao CP, Xiao PF, Liu M (2010) Crustal deformation of the eastern Tibetan plateau revealed by magnetotelluric imaging. Nat Geosci 3(5):358-362

Bhattacharyya BK, Leu LK (1975) Spectral analysis of gravity and magnetic anomalies due to two-dimensional structure. Geophysics 40:993-1013

Bilim F, Akaya T, Aydemirb A, Kosaroglu S (2016) Curie point depth, heat-flow and radiogenic heat production deduced from the spectral analysis of the aeromagnetic data for geothermal investigation on the Menderes Massif and the Aegean Region, westernTurkey. Geothermics 60:44-57

Burchfiel BC, Wang E (2003) Northwest-trending, Middle Cenozoic, left-lateral faults in southern Yunnan, China, and their tectonic significance. J Struct Geol 25(5):781-792

Chang L, Ding ZF, Wang CY (2015) Upper mantle anisotropy beneath the southern segment of North South-tectonic belt, China. Chin J. Geophys 58(11):4052-4067 (in Chinese)

Chen Z, Burchfiel BC, Liu Y, King RW, Royden LH, Tang W, Wang E, Zhao J, Zhang X (2000) Global Positioning System measurements from eastern Tibet and their implications for India/Eurasia intercontinental deformation. J Geophys Res 105(B7):16215-16227

Chen Y, Zhang ZJ, Sun CQ, Badal J (2013) Crustal anisotropy from Moho converted Ps wave splitting analysis and geodynamic implications beneath the eastern margin of Tibet and surrounding regions. Gondwana Res 24:946-957

Cheng YZ, Tang J, Chen XB, Dong ZY, Xiao QB, Wang LB (2015) Electrical structure and seismogenic environment along the border region of Yunnan, Sichuan and Guizhou in the south of the North-South seismic belt. Chin J Geophys 58(11):3965-3981

Cooper GRJ, Cowan DR (2005) Differential reduction to the pole. Comput Geosci 31:989-999

Deng JM, Jin MP, Zhao JB, Gao Q, Chen J (2014) Tectonic implications from the distribution map of the crust thickness and Poisson's ratio in the Yunnan area. Earthq Res China 30(4):583-596

Dimitriadis K, Tselentis GA, Thanassoulas K (1987) A basic program for 2-D spectral analysis of gravity data and source-depth estimation. Comput Geosci 13:549-560

Eppelbaum LV, Pilchin AN (2006) Methodology of Curie discontinuity map development for regions with low thermal characteristics: an example from Israel. Earth Planet Sci Lett 243:536-551

Gao GM, Kang GF, Bai CH, Li GQ (2013) Distribution of the crustal magnetic anomaly and geological structure in Xinjiang, China. J Asian Earth Sci 77:12-20

Gao GM, Kang GF, Bai CH, Wen LM (2015a) Study on crustal magnetic anomalies and Curie surface in Southeast Tibet. J Asian Earth Sci 97:169-177

Gao GM, Kang GF, Li GQ, Bai CH (2015b) Crustal magnetic anomaly in the Ordos region and its tectonic implications. J Asian Earth Sci 109:63-73

Gao GM, Kang GF, Li GQ, Bai CH (2015c) Crustal magnetic anomaly and Curie surface beneath Tarim Basin, China, and its adjacent area. Can J Earth Sci 52:357-367

Gao GM, Kang GF, Li GQ, Bai CH, Wu YY (2017) An analysis of crustal magnetic anomaly and Curie surface in west Himalayan syntaxis and adjacent area. Acta Geod Geophys 52:407-420

Gao GM, Shi L, Kang GF, Wu YY, Bai CH, Wen LM, Hou J (2018) Analysis of the lithospheric magnetic anomalies and tectonics in continental China and the adjacent regions using CHAMP satellite data. Stud Geophys Geod 62:1-19

Gao GM, Hou J, Kang GF, Bai CH, Wen LM, Zhao H, Shi L (2019) Crustal thickness and lithospheric thermal state beneath the Junggar Basin and 
adjacent Mountain Ranges, Northwest China. J Asian Earth Sci. https:// doi.org/10.1016/j.jseaes.2019.02.024

Guan Y, Wang AJ, Cao DH, Qin DH (2004) East-west structures in the Sanjiang region, western Yunnan and their implications. Acta Geol Sin 78(4):494-499

Hamed S, Nabi AE (2012) Curie point depth beneath the Barramiya-Red Sea coast area estimated from spectral analysis of aeromagnetic data. J Asian Earth Sci 43:254-266

Hao SJ, Gao HG, Wang CH (1982) Isothermal surface of curie temperature around the Beijing area and its relation to earthquakes. Acta Geophs Sin 25(3):264-269

Hemant K, Mitchell A (2009) Magnetic field modelling and interpretation of the Himalayan-Tibetan Plateau and adjoining north Indian Plains. Tectonophysics 478:87-99

Hu SB, He LJ, Wang JY (2000) Heat flow in the continental area of China: a new data set. Earth Planet Sci Lett 179:407-419

Hu SB, He LJ, Wang JY (2001) Compilation of the heat flow data in the China continental area. Chin J Geophys 44(5):611-626 (in Chinese)

Hu JF, Badal J, Yang HY, Li GQ, Peng HC (2018) Comprehensive crustal structure and seismological evidence for lower crustal flow in the southeastern margin of Tibet revealed by receiver functions. Gondwana Res 55:42-59

Ibrahim A, Halil IK, Ali K (2005) Curie-point depth map of Turkey. Geophys J Int 162:633-640

Jiang GZ, Gao P, Rao S, Zhang LY, Tang XY, Huang F, Zhao P, Pang ZH, He LIJ, Hu SB, Wang JY (2016) Compilation of heat flow data in the continental area of China(4th edition). Chin J Geophys 59(8):2892-2910 (in Chinese)

Kan RJ, Hu HX, Zeng RS, Mooney WD, McEvilly TV (1986) Crustal structure of Yunnan province, People's Republic of China, from seismic refraction profiles. Science 234(4775):433-437

Langston CA (1979) Structure under Mount Rainier, Washington, inferred from teleseismic body waves. J Geophys Res 84(B3):4749-4763

Leloup PH, Robin L, Tapponnier P, Schärer U, Zhong DL, Liu XH, Zhang LS, Ji SC (1995) The Ailao Shan-Red River shear zone (Yunnan, China), Tertiary transform boundary of Indochina. Tectonophysics 251:3-84

Li YH, Wu QJ, Tian XB, Zhang RQ, Pan JT, Zeng RS (2009) Crustal structure in the Yunnan region determined by modeling receiver functions. Chin Geophys 52(1):67-80 (in Chinese)

Li CF, Wang J, Lin J, Wang T (2013) Thermal evolution of the North Atlantic lithosphere: new constraints from magnetic anomaly inversion with a fractal magnetization model. Geochem Geophys Geosyst 14:5078-5105

Li R, Tang J, Dong ZY, Xiao QB, Zhan Y (2014) Deep electrical conductivity structure of the southern area in Yunnan Province. Chin J Geophys 57(4):1111-1122 (in Chinese)

Lou H, Wang C (2005) Wavelet analysis and interpretation of gravity data in Sichuan-Yunnan region, China. Acta Seismol Sin 5(27):515-523

Lu RS, Mariano J, Willen DE (2003) Differential reduction of magnetic anomalies to the pole on a massively parallel computer. Geophysics 68(6):1945-1951

Maden N (2010) Curie-point depth from spectral analysis of magnetic data in Erciyes stratovolcano (Central TURKEY). Pure Appl Geophys 167:349-358

Manea M, Manea VC (2011) Curie point depth estimates and correlation with subduction in Mexico. Pure Appl Geophys 168:1489-1499

Maule CF, Purucker ME, Olsen N, Mosegaard K (2005) Heat flux anomalies in Antarctica revealed from satellite magnetic data. Science 309:464-467

Maus S (2010a) An ellipsoidal harmonic representation of Earth's lithospheric magnetic field to degree and order 720. Geochem Geophys Geosyst $11(6): 1-12$

Maus S (2010b) Enhanced Magnetic Model (EMM2010). http://ngdcnoaa.gov/ geomag/EMM/index.html. Accessed Aug 2010

Maus S, Barckhausen U, Berkenbosh H, Bournas N, Brozena J, Childers V Dostaler F, Fairhead JD, Finn C, von Frese RRB, Gaina C, Golynsky S, Kucks R, Luhr H, Milligan P, Mogren S, Muller RD, Olesen O, Pilkington M, Saltus R, Schreckenberger B, Thebault E, Tontini FC (2009) EMAG2: a 2-arc min resolution earth magnetic anomaly grid compiled from satellite, airborne, and marine magnetic measurements. Geochem Geophys Geosyst 10:Q08005. https://doi.org/10.1029/2009GC002471

Mayhew MA (1982) Application of satellite magnetic anomaly data to Curie isotherm mapping. J Geophys Res 87:4846-4854

Nwobgo PO (1998) Spectral prediction of magnetic source depths from simple numerical models. Comput Geosci 24:847-852
Nyabeze PK, Gwavava O (2016) Investigating heat and magnetic source depths in the Soutpansberg Basin, South Africa: exploring the Soutpansberg Basin Geothermal Field. Geotherm Energy 4(1):8. https://doi. org/10.1186/s40517-016-0050-z

Oliver A 1990. The database management of piling induced ground vibrations Durham theses, Durham University. Available at Durham E-Theses. http:// etheses.dur.ac.uk/6154/

Owens TJ, Zandt G, Taylor SR (1984) Seismic evidence for an ancient rift beneath the Cumberland Plateau, Tennessee: a detailed analysis of broadband teleseismic P waveforms. J Geophys Res 89(B9):7783-7795

Purucker ME, Clark DA (2011) Mapping and interpretation of the lithospheric magnetic field, in geomagnetic observations and models. In: Mandea M, Korte M, editors. IAGA Spec Sopron Book Ser. 5, Springer, Netherlands, pp 311-338

Purucker ME, Langel RA, Rajaram M, Raymond C (1998) Global magnetization models with a priori information. J Geophys Res 103(B2):2563-2584

Rajaram M, Anand SP, Hemant K, Purucker ME (2009) Curie isotherm map of Indian subcontinent from satellite and aeromagnetic data. Earth Planet Sci Lett 281:147-158

Ravat D, Pignatelli A, Nicolosi I, Chiappini M (2007) A study of spectral methods of estimating the depth to the bottom of magnetic sources from nearsurface magnetic anomaly data. Geophys J Int 169:421-434

Replumaz A, Tapponnler P (2003) Reconstruction of the deformed collision zone between India and Asia by backward motion of lithospheric blocks. J Geophys Res 108(B6):2285

Saada SA (2016) Curie point depth and heat flow from spectral analysis of aeromagnetic data over the northern part of Western Desert, Egypt. J Appl Geophys 134:100-111

Saibi H, Aboud E, Gottsmann J (2015) Curie point depth from spectral analysis of aeromagnetic data for geothermal reconnaissance in Afghanistan. J Afr Earth Sc 111:92-99

Salazar JM, Vargas CA, Leon H (2017) Curie point depth in the SW Caribbean using the radially averaged spectra of magnetic anomalies. Tectonophysics 694:400-413

Schoenbohm LM, Burchfiel BC, Liangzhong C (2006) Propagation of surface uplift, lower crustal flow, and Cenozoic tectonics of the southeast margin of the Tibetan Plateau. Geology 34(10):813-816

She YW, Fu GY (2019) Viscosities of the crust and upper mantle constrained by three-dimensional GPS rates in the Sichuan-Yunnan fragment of China. Earth Planets Space 71:33. https://doi.org/10.1186/s40623-019-1014-x

Shen NH, Li CH, Zhang GB, Wang HX (1986) Curie isotherm depths calculation from aeromagnetic anomalies over Xikang and Yunnan continental paleorift zone. Chin J Geophys. 29(5):496-502

Shen CY, Yang GL, Tan HB, Xuan BS, Wu GJ, Wang J (2015) Gravity anomalies and crustal density structure characteristics of profile Weixi-Guiyang. Chin J Geophys 58(11):3952-3964 (in Chinese)

Shi PL, Yang TN, Liang MJ, Xue CD, Fan JW (2015) Temporal and spatial variation in the Cenozoic strain of the strain of the Sanjiang orogenic belt, SW China: a brief review and new observations. Acta Petrol Sin 31(11):3331-3352

Speranza F, Minelli L, Pignatelli A, Gilardi M (2016) Curie temperature depths in the Alps and the Po Plain (northern Italy): comparison with heat flow and seismic tomography data. J Geodyn 98:19-30

Sun J, Xu CF, Jiang Z, Shi SL, Wang JJ, He M (1989) The electrical structure of the crust and upper mantle in the west part of Yunnan province and its relation to crustal tectonics. Seismol Geol 11(1):35-45

Tanaka A, Okubo Y, Matsubayashi O (1999) Curie point depth based on spectrum analysis of the magnetic anomaly data in East and Southeast Asia. Tectonophysics 306:461-470

Teng JW (1994) Lithospheric physics and dynamics of the Kang-Dian tectonic zone. Science Press, Beijing (in Chinese)

Thébault E, Purucker M, Kathryn A, Langlais WB, Sabaka TJ (2010) The magnetic field of the earth's lithosphere. Space Sci Rev 155:95-127

Utada H, Neki M, Kagiyama T (2000) A study of annual variations in the geomagnetic total intensity with special attention to detecting volcanomagnetic signals. Earth Planets Space 52:91-103. https://doi.org/10.1186/ BF03351617

Utada H, Shimizu H, Ogawa T, Maeda T, Furumura T, Yamamoto T, Yamazaki N, Yoshitake Y, Nagamachi S (2011) Geomagnetic field changes in response to the 2011 off the Pacific Coast of Tohoku Earthquake and 
Tsunami. Earth Planet Sci Lett 311(1-2):11-27. https://doi.org/10.1016/j. epsl.2011.09.036

Wang E, Burchfiel BC (2000) Late Cenozoic to Holocene deformation in southwestern Sichuan and adjacent Yunnan, China, and its role in formation of the southeastern part of the Tibetan Plateau. Geol Soc Am Bull 112(3):413-423

Wang JY, Huang SP (1988) Compilation of heat flow data for continental area of China. Sci Geol Sin 33(2):197-204

Wang J, Li CF (2015) Crustal magmatism and lithospheric geothermal state of western North America and their implications for a magnetic mantle. Tectonophysics 638:112-125

Wang JA, Xu Q, Zhang WR (1990) Heat flow data and some geologic-geothermal problems in Yunnan Province. Seismol Geol 12(4):367-377

Wang CY, Mooney WD, Wang X, Wu J, Lou H, Wang F (2002) Study on 3-d velocity structure of crust and upper mantle in Sichuan-Yunnan region, China. Acta Seismol Sin 1:1-16

Wang XB, Yu N, Gao S, Luo W, Cai XL (2017) Research progress in research on electrical structure of crust and upper mantle beneath the eastern margin of the Tibetan plateau. Chin J Geophys 60(6):2350-2370 (in Chinese)

Wasilewski PJ, Mayhew MA (1992) The Moho as a magnetic boundary revisited. Geophys Res Lett 19:2259-2262

Wen LM, Kang GF, Bai CH, Gao GM, Zheng AR, An BL (2017) Crustal Magnetic Anomalies and Geological Structure in Yunnan Region. Chin J Geophys. 60(9):3493-3504

Wen LM, Badal J, Hu JF (2019) Anisotropic H-k stacking and (revisited) crustal structure in the southeastern margin of Tibet. J Asian Earth Sci 169:93-104

Wu JP, Yang T, Wang WL, Ming YH, Zhang TZ (2013) Three dimensional P-wave velocity structure around Xiaojiang fault system and its tectonic implications. Chin J Geophys 56(7):2257-2267 (in Chinese)

Xiang CY, Zhou ZH (2000) Relationship between Seismicity and Geothermal Structure of the Lithosphere in Yunnan Province. China. Earthquake Research in China 16(3):263-272

Xiong SQ, Ding YY, Li ZK (2014) Characteristics of Magnetic Basement Depth Beneath China Mainland. Chinese J. Geophys. (in Chinese) 57(12):3981-3993

Xiong SQ, Yang H, Ding YY, Li ZK (2016) Characteristics of Chinese continent Curie point isotherm. Chinese J. Geophys. (in Chinese) 59(10):3604-3617
Xu WY (2009) Physics of Electromagnetic Phenomena of the Earth. University of Science and Technology of China Press, He Fei, pp 216-243

Xu MJ, Wang LS, Liu JH, Zhang K, Li H, HuD S, Xu Z (2005) Crust and uppermost mantle structure of the Ailaoshan-Red River fault from receiver function analysis. Sci China Ser D Earth Sci 35(8):729-737

Xu XM, Ding ZF, Shi DN, Li XF (2013) Receiver function analysis of crustal structure beneath the eastern Tibetan plateau. J Asian Earth Sci 73:121-127

Xue M, Wang S, Xu XY, Hu JF (2017) Structure of the mantle transition zone under the Yunnan region and its geodynamic implications. Chin Sci Bull 62:1752-1765 (in Chinese)

Yu CQ, Zhang G, Wang XB, Luo W, Li DE, Cai XL, Guo ZM (2017) Deep electrical resistivity structure of Sanjiang Area of west Yunnan and its significance. Chin J. Geophys 60(6):2385-2396 in Chinese)

Yuan YS, Ma YS, Hu SB, Guo TL, Fu XY (2006) Present-day geothermal characteristics in South China. Chin J Geophys 49(4):1118-1126 (in Chinese)

Yury PT, Konstantin VN, Andrey Al, Oleg MB (2018) Sources of the lithosphere magnetic field based on magnetic data obtained at different heights. Earth Planets Space 70(1):183. https://doi.org/10.1186/s40623-018-0955-9

Zha XH, Lei JS (2013) Crustal thickness and Poisson's ratio beneath the Yunnan region. Sci China Earth Sci 56(4):693-702

Zhang PZ (2013) A review on active tectonics and deep crustal processes of the Western Sichuan region, eastern margin of the Tibetan Plateau. Tectonophysics 584:7-22

Zhang BW, Zhao CP, Zhou LQ (2015) Crustal Thickness and Poisson's Ratio beneath the East Boundary of Sichuan-Yunnan Block from Receiver Functions. Earthquake 35(1):55-64

Zhang ZL, Zhao YF, Gu J (2017) Analysis of characteristics of lithosphere magnetic field change anomalies in Xiaojiang fault and its adjacent area. J Seismol Res 40(3):372-437

Zhao D, Yu S, Ohtani E (2011) East Asia: seismotectonics, magmatism and mantle dynamics. J Asian Earth Sci 40:689-709

Zhou ZH, Xiang CY, Qin YX, Zhao JM (1997) Study on deep heat flow in Yunnan, China. Northwestern Seismol J 19(4):51-57

\section{Publisher's Note}

Springer Nature remains neutral with regard to jurisdictional claims in published maps and institutional affiliations.

\section{Submit your manuscript to a SpringerOpen ${ }^{\odot}$ journal and benefit from:}

- Convenient online submission

- Rigorous peer review

- Open access: articles freely available online

- High visibility within the field

- Retaining the copyright to your article

Submit your next manuscript at $\boldsymbol{\nabla}$ springeropen.com 